\title{
Cellular heterogeneity of CFTR expression and function in the lung: implications for gene therapy of cystic fibrosis
}

\author{
Q inshi J iang and John F E ngelhardt
}

D epartment of A natomy and Cell B iology and D epartment of Internal M edicine at the U niversity of Iowa School of Medicine, I owa City, I owa 52242, USA

Cystic fibrosis (CF) has become a paradigm disorder for the clinical testing of gene therapies in the treatment of inherited disease. In recent years, efforts directed at gene therapy of CF have concentrated on improving gene delivery systems to the airway. Surrogate endpoints for complementation of CFTR dysfunction in the lung have been primarily dependent on correction of chloride transport abnormalities. However, it is now clear that the pathophysiology of CF airways disease is far more complex than can be solely attributed to altered chloride permeability. For example, in addition to functioning as a chloride channel, CFTR also has been implicated in the regulation of other apical membrane conductance pathways through interactions with the amiloride sensitive epithelial sodium channel (ENaC) and the outwardly rectifying chloride channel (ORCC). Superimposed on this functional diversity of CFTR is a highly regulated pattern of CFTR expression in the lung. This heterogeneity occurs at both the level of CFTR protein expression within different cell types in the airway and the anatomical location of these cells in the lung. Potential targets for gene therapy of CF include ciliated, non-ciliated, and goblet cells in the surface airway epithelium as well as submucosal glands within the interstitium of the airways. Each of these distinct cellular compartments may have functionally distinct roles in processes which affect the pathogenesis of CF airways disease, such as fluid and electrolyte balance. However, it is presently unclear which of these cellular targets are most pathophysiologic relevant with regard to gene therapy. Elucidation of the underlying mechanisms of CFTR function in the airway will allow for the rational design of gene therapy approaches for CF lung diseases. This review will provide a summary of the field's current knowledge regarding CFTR functional diversity in the airway and the implications of such diversity for gene therapies of CF lung disease.

Keywords: Cystic Fibrosis; CFTR; Lung; Airway; Gene Therapy

Correspondence: John F. E ngelhardt, D epartment of A natomy and Cell B iology, $U$ niversity of I owa School of M edicine, 51 N ewton R oad, R oom 1-101 B SB, I owa City, lowa 52242, USA

R eceived 28 A pril 1997; revised 140 ctober 1997; accepted 22

O ctober 1997 


\section{Introduction}

Cystic fibrosis is the most common autosomal recessive disease in the Caucasian population affecting 1:2000-1:3000 births each year. ${ }^{1}$ A lthough multiple organs are affected in this disease, the most severe pathology occurs in the lung and results in the production of abnormally viscous mucus, poor mucociliary clearance, chronic bacterial infections, bronchiectasis, and eventually pulmonary failure and death. The molecular defect in cystic fibrosis was elucidated following the cloning of the cystic fibrosis transmembrane conductance regulator (CFTR) gene, ${ }^{2-4}$ which encodes an epithelial chloride channel. Respiratory complications in CF, caused by the lack of CFTR mediated chloride transport in epithelial cells of the lung, are believed to be the result of a combination of factors including abnormally thick mucus secretions, impaired mucociliary clearance, and decreased bacterial killing. ${ }^{1,5,6} \mathrm{D}$ espite the numerous advances associating primary defects in CF airway epithelium with CFTR dysfunction, the exact mechanism(s) which result in an elevated susceptibility to infection specifically with Pseudomonas aeruginosa remain obscure. Central to the current confusion associated with the etiology of CF lung disease is a lack of understanding about what functions CFTR has in the normal airway. $D$ espite this large gap in knowledge, cystic fibrosis has developed into a paradigm disease model for human gene therapy. N umerous phase I gene therapy protocols directed at evaluating the efficacy and toxicity of gene transfer to the airway have been initiated for recombinant adenovirus, adeno-associated virus, and liposomes. ${ }^{7-20}$ H owever, without a concrete knowledge of the pathophysiologic relevant cellular targets and CFTR functions in the lung, progress toward phase II efficacy trials for CF will be impaired. This manuscript will review several aspects of CFTR physiology in the lung to portray the complexities which may be associated with future gene therapy trials for CF. Q uestions this review will address include: 1) What are the cellular sites of CFTR expression in the lung? 2) What is the current understanding about cellular functions of CFTR in the lung? 3) How might cell type specific compartmentalization of CFTR expression play an important role in the regulation of fluid and electrolyte transport in the airways? and 4) What are the implications of multiple functionally distinct cellular targets in the lung for gene therapy of CF? This review will present a general model of how CFTR may function in the airway within numerous distinct cellular compartments to regulate electrolyte, fluid, and mucous secretions. Central to this model is an appreciation for the limitations of current in vitro and in vivo animal models to study CFTR function. Such limitations include the potential for highly regulated and compartmentalized expression of both CFTR and other ion channels in the airway which may be necessary for normal airway function. Ultimately, a better understanding of such functional diversity will aid in the rational development of treatments (both pharmacologic and gene therapy) for $C F$ airways disease.

\section{Heterogeneity of CFTR-expressing cell types in the lung}

The characterization of CFTR expression within human lung has provided the foundation for understanding what cellular sites in the lung may be pathophysiologically important in CF lung disease. Initial reports using PCR analysis of human lung have demonstrated that, on average, only several copies of CFTR mRNA are present in lung epithelial cells. ${ }^{21}$ Furthermore, variation in the splicing of CFTR transcripts within the $C F$ population has suggested that as little as $8-15 \%$ of normal CFTR message is required for normal lung function. ${ }^{22,23}$ Studies localizing CFTR expression in the proximal human bronchus have demonstrated that CFTR protein and mRNA are expressed predominantly in submucosal glands and to a lesser extent in the surface airway epithelium. ${ }^{24-26}$ Surface airway epithelial cells were seen to express CFTR at high levels in an infrequent population of non-ciliated cells surrounding gland duct openings. ${ }^{24}$ In contrast, submucosal glands, which are located within the cartilaginous airways, abundantly expressed CFTR . These structures are composed of numerous interconnecting ducts and tubules which regulate the flow of serous and mucous secretions into the airway. The pattern of CFTR expression within the submucosal glands is extremely heterogeneous with regard to CFTR-expressing cellular phenotypes. The highest abundance of CFTR is located at the most distal ends of glands in nearly all serous cells. In contrast, collecting and ciliated ducts of submucosal glands express CFTR at extremely high levels in 1-3\% of cells. Hence, the cell types and the pattern of CFTR expression within submucosal glands have proven to be 
very heterogeneous and demonstrate the potential complexities associated with targeting this region by gene therapy.

A nalysis of CFTR expression in the distal regions of the lung is also very heterogeneous and is seen within a subset of non-ciliated bronchiolar and alveolar epithelial cells. ${ }^{27}$ This pattern suggests a recurrent theme of highly regulated expression as seen in submucosal gland ducts. Of importance when evaluating CFTR expression patterns in the airway, is a concrete understanding concerning the sensitivity of assays used for detection. For example, alternative more sensitive methods of detecting CFTR expression in airway cell types have assessed chloride channel function. A Ithough CFTR protein expression is undetectable in ciliated cells by immunocytochemical techniques, studies utilizing intracellular microelectrodes to measure apical membrane $\mathrm{Cl}^{-}$permeabilities in freshly excised proximal airway tissues have suggested the CFTR is also expressed at low levels in ciliated cells. ${ }^{28,29}$ Such findings underscore the highly regulated nature of CFTR expression in the airway.

Critical to our understanding of how cellular compartmentalization of CFTR expression in the airway may regulate fluid and electrolyte balance is the distribution of other channels which may function coordinately with CFTR to affect these processes. For example, Figure 1 depicts the co-localization of CFTR and $\mathrm{Na}^{+} / \mathrm{K}^{+}$- ATPase within proximal surface airway epithelial cells and gland ducts. This figure demonstrates high levels of CFTR expression in a single airway epithelial cell type which also expresses high levels of basolateral $\mathrm{Na}^{+} / \mathrm{K}^{+}$- ATPase. Channels such as the epithelial sodium channel $(\mathrm{ENaC})$ and the outwardly rectifying chloride channel (ORCC), which may in part be regulated by CFTR (see section below), are other important candidates that may determine the overall function of any one particular CFTR -expressing cell type.

In addition to airway cell types which express CFTR as an apical membrane chloride channel, studies evaluating CF primary defects in mucous processing have indirectly suggested that CFTR may also function within mucous-secreting cell types. Such studies have identified CF-associated biochemical alterations in secreted glycoproteins, including increased sulfation and fucosylation together with decreased sialylation. ${ }^{30-37} \mathrm{H}$ owever, the potential for secondary effects of bacterial infection in these studies has caused considerable debate in this area, ${ }^{38}$ as indicated by a report which shows no abnormalities in the biochemical properties of $\mathrm{CF}$ mucus. ${ }^{39} \mathrm{R}$ ecently, the use of a human bronchial xenograft model of $C F$ and non-CF airways has allowed for the comparison of mucin biochemical properties in the absence of bacterial infection and goblet cell hyperplasia. These studies have confirmed the existence of increased sulfation in CF airway mucin as compared with non-CF mucin. ${ }^{33}$ F urthermore, definitive studies have demonstrated that correction of sulfation defects in CF bronchial xenografts can be accomplished with both liposome and recombinant adenoviral mediated gene transfer of the CFTR CD NA.$^{34}$ Such studies have conclusively demonstrated that CFTR functions within glycoprotein processing pathways of airway goblet cells. The paradox regarding undetectable levels of CFTR gene expression in airway goblet cells ${ }^{24}$ (Figure 1, despite CF functional defects in mucous processing (ie sulfation and sialylation), suggests that the level of CFTR protein needed to achieve proper glycoprotein processing may be quite low.

In summary, CFTR expression in the airway is highly regulated. This regulation is evident in the cell type specific partitioning of CFTR expression as well as the level at which CFTR protein is expressed. This cellular heterogeneity of CFTR expression in the airway is summarized in Figure 2. Five main cell types within the airway are shown, including basal, intermediate, goblet, ciliated, and non-ciliated columnar cells (Figure 2a). The level and cellular location of CFTR expression, as suggested by functional and histologic data, is schematically represented in Figure $2 \mathrm{~b}$. Such a uniquely regulated distribution of CFTR expression in the airway highlights the potential complexities associated with gene targeting to the CF lung and poses several interesting questions. How do different cell types in the airway, which express CFTR at various levels, control the volume and ionic composition of airway surface fluid? I s the level of CFTR expression linked to cellular compartmentalized function? What is the pathophysiologic involvement of each of these CFTR-expressing cellular compartments in CF airways disease? Such questions are extremely relevant in designing strategies to correct the CF phenotype by gene targeting. For example, will gene targeting require regulated CFTR expression, which reconstitutes the endogenous patterns, to restore all CFTR functions in the airway? To fully appreciate these implications for gene therapy, one must first understand what functional roles CFTR may have in the airway and how these functions relate to disease. 


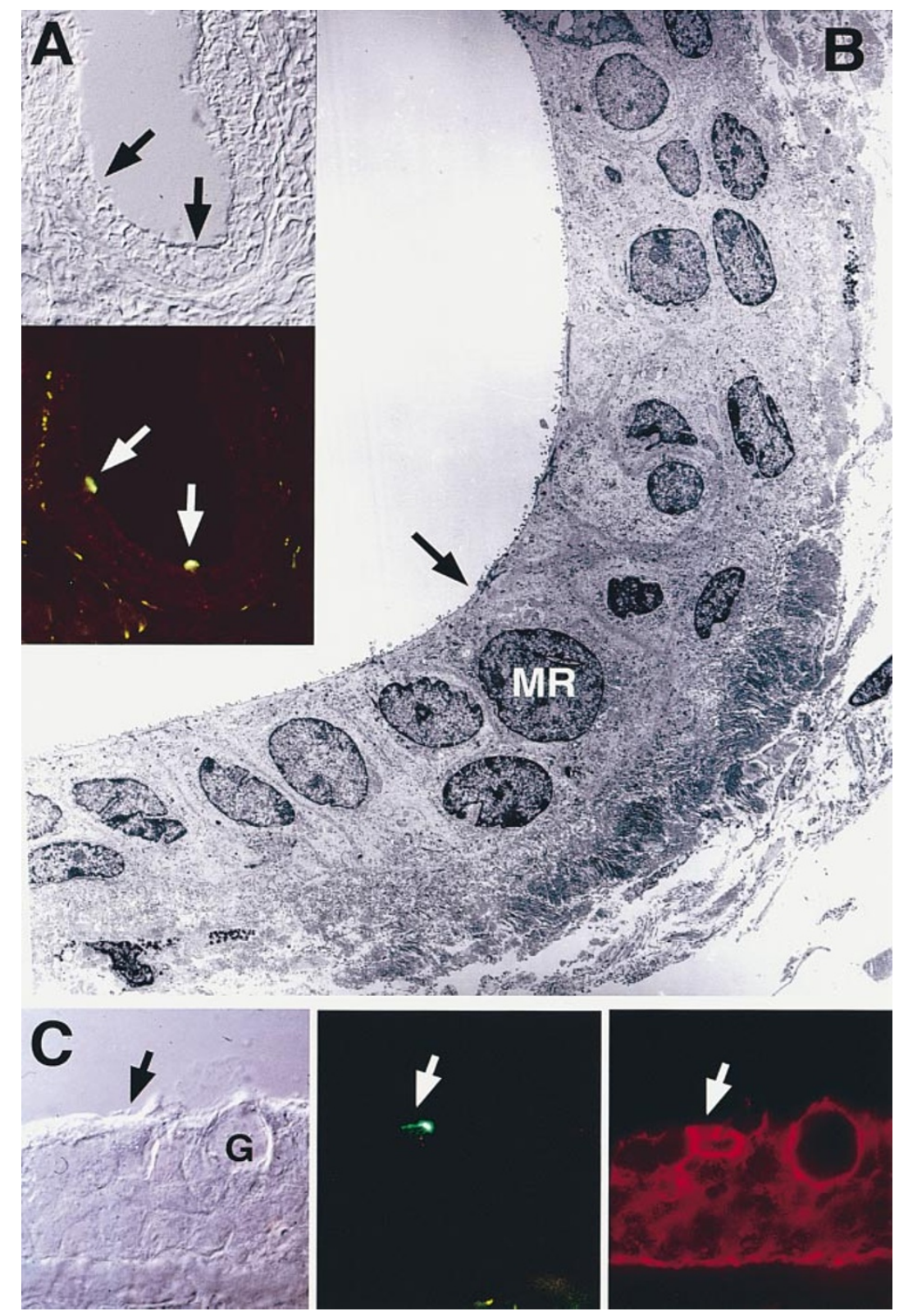

Figure 1 H eterogeneous expression of CFTR in human bronchial submucosal gland and surface airway epithelia.

I mmunofluorescent staining for CFTR in Panel A demonstrates high levels of CFTR protein expression in a subset of submucosal gland duct cells (arrows). ${ }^{24}$ Nomarski and FITC fluorescent photomicrographs are shown in the top and bottom of Panel A, respectively. By analogy to amphibian skin mitochondrial rich (MR ) cells, the electron photomicrograph of a submucosal gland duct shown in Panel B points to a morphologically similar cellular phenotype which may be the site of CFTR expression in this region. In the airway, a similar heterogeneous staining pattern of CFTR expression is observed in a subset of surface airway epithelial cells (Panel C). Photomicrographs in Panel C depict Nomarski (left), anti-CFTR (FITC, center), and anti-N ${ }^{+} / \mathrm{K}^{+}-\mathrm{ATP}$ ase (Texas R ed, right) staining patterns. The composite of channels found in CFTR-expressing cells may play an important role in the cellular partitioning of epithelial functions involved in the regulation of fluid and electrolyte movement across the airway. In support of this hypothesis, Panel $\mathrm{C}$ demonstrates a higher level of basolaterally expressed $\mathrm{Na}^{+} / \mathrm{K}^{+}-\mathrm{A}$ TPase within cell types which express high levels of CFTR. A nother important feature of CFTR expression and function in the airway is that CFTR protein is undetectable in goblet cells (marked G). A s discussed in the body of this manuscript, this finding contradicts studies which suggest that CFTR dysfunction in goblet cells leads to intracellular glycoprotein processing defects in secreted CF mucin. These studies have suggested that very small levels of CFTR (beyond the level of sensitivity of immunocytochemical assays) may be needed for correct glycoprotein processing. Such findings underscore the diversity of CFTR functions in the airway which may in part be regulated at the level of CFTR expression. 


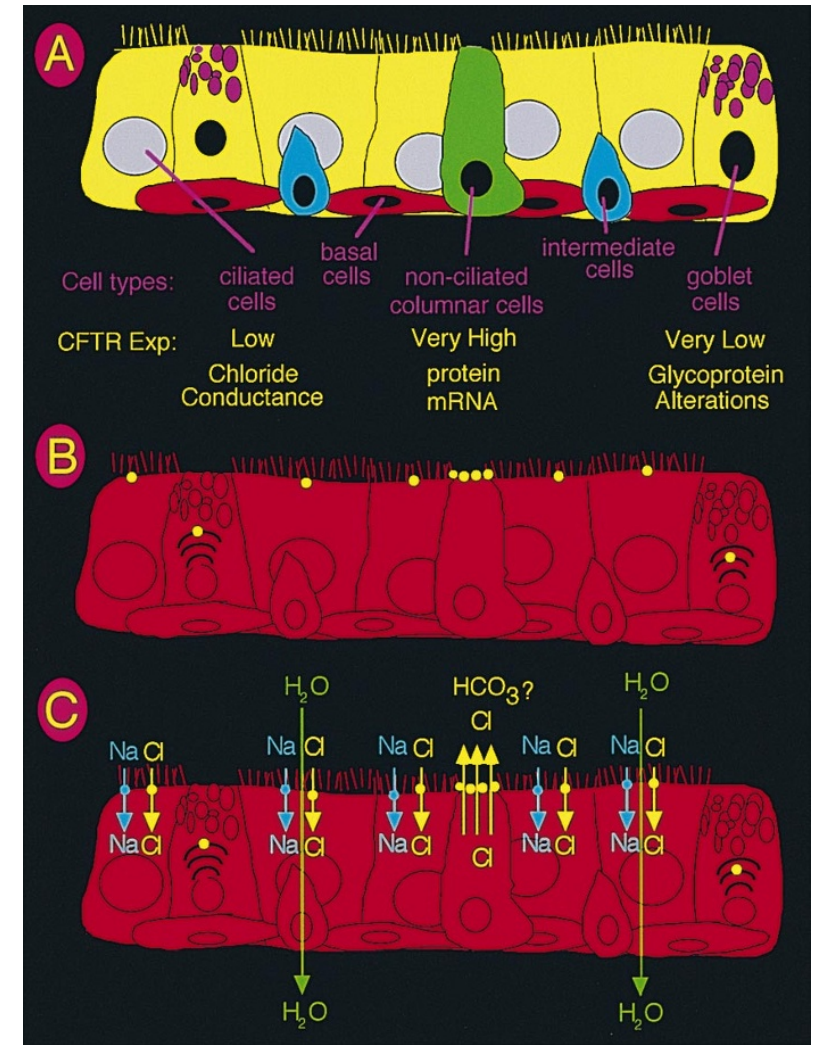

Figure 2 Model for cellular compartmentalization of CFTR expression and function in the airway. The level of CFTR expression in the airway is highly regulated within different cell types. Panel A schematically depicts the five most abundant cell types in the proximal surface airway epithelium (ciliated, basal, goblet, non-ciliated columnar, and intermediate cells). Classification of these various cell types has been traditionally based on the following morphologic criteria: ciliated cell - the presence of apical cilia; basal cell cuboidal appearing cell of high nuclear to cytoplasmic ratio with nuclei in the lowest layer of epithelium, direct contact with the basal lamina and no luminal contact; goblet cells the presence of mucous granules; non-ciliated columnar cells - the absence of cilia and secretory granules but with an apical boundary at the luminal surface; and intermediate cells - cells adjacent to the basal lamina with cytoplasm extending upward into the epithelium but not contacting the luminal surface. The level of CFTR in these cell types can be inferred from several experimental studies which have evaluated CFTR expression at the protein, mR NA, and functional level. CFTR expression in ciliated cells is extremely low and can be detected at the electrophysiologic level of chloride conductance ${ }^{28,29}$ but not by immunocytochemical studies localizing protein. ${ }^{24}$ In contrast, a subpopulation of non-ciliated cells (marked in green) expresses extremely high levels of CFTR protein and mRNA. ${ }^{24,27}$ Low levels of CFTR expression in goblet cells is inferred by the CF associated phenotype of increased sulfation, decreased sialylation, and increased fucosylation in secreted mucin. ${ }^{31-33,35}$ However, protein and mRNA cannot be detected in goblet cells using standard histologic procedures of immunocytochemistry and in situ hybridization. ${ }^{24}$ Panel $B$ summarizes the cellular hetero-

\section{Multifunctional CFTR: Cellular Functions of CFTR in the Lung}

\author{
CFTR is an Apical Membrane Chloride \\ Channel and Regulator of other Channels
}

CFTR is a membrane protein that functions as a CA M P activated, chloride selective ion channel ${ }^{40,41} \mathrm{M}$ utations in CFTR associated with severe lung disease, such as $\Delta \mathrm{F} 508$ or $\mathrm{G} 551 \mathrm{D}$, reduce or abolish CA M P-activated chloride permeability by at least two mechanisms: reduced delivery of the protein to the apical membrane, and/or impaired activation of $\mathrm{Cl}^{-}$conductance. ${ }^{42,43}$ Electrolyte transport defects in the CF airway epithelium have been extensively characterized in CF nasal epithelia, both in vitro and in vivo. ${ }^{44-46}$ Such studies have demonstrated that, in addition to a defective CA M P inducible chloride secretory response, CF nasal epithelia have increased levels of amiloride-sensitive

geneity of CFTR expression levels in the proximal surface airway epithelium. The abundance of CFTR channels is denoted by the frequency of yellow dots. N ote the placement of CFTR channels within the Golgi compartment of goblet cells as compared to the apical membrane of ciliated and nonciliated columnar cells. A Ithough it is not noted in this Figure, CFTR is also likely to be expressed within intracellular compartments of other cell types in the airway as suggested by biochemical alterations in surface glycoproteins of $C F$ epithelia. Panel $C$ proposes a model for cellular partitioning of CFTR functions involved in regulating fluid and electrolyte transport in the airway. This model is based on the well studied mechanisms of cellular partitioning of chloride and sodium transport functions in amphibian skin. Of interest is the cellular expression pattern of other channels important in salt movement across the airway such as $\mathrm{ENaC}$ (marked by blue circles). Since the activity of E N aC has been shown to be functionally regulated by CFTR, the cellular partitioning of these two channels is important from a mechanistic and gene therapy standpoint. This model proposes that $\mathrm{ENaC}$ is co-expressed with low levels of CFTR in ciliated cells and that these cell types function to absorb salt and water in the maintenance of surface airway fluid and electrolyte balance. Such a hypothesis is consistent with the ubiquitous expression of $\mathrm{ENaC}$ mRNA in the majority of surface airway epithelial cells ${ }^{106,107}$ and the functional detection of CFTR in ciliated cells using intracellular microelectrodes and freshly excised nasal tissue. ${ }^{28,29}$ In contrast, non-ciliated columnar cells which express extremely high levels of CFTR are proposed to have a different function than ciliated cells in the maintenance of airway surface fluid and electrolyte composition. This cell type is modeled after the mitochondrial rich cell of amphibian skin. Such a cell type in the airway may serve to secrete chloride (and/or bicarbonate) in the fine tuning of surface airway electrolyte composition and/or pH. Given the infrequent nature of this cell type in the airway, it is not proposed as a significant source of fluid transport in the airway. Such a model proposes that hydration of the airways must occur through alternative sources such as submucosal glands. 
$\mathrm{Na}^{+}$conductance. This $\mathrm{CF}$ associated sodium hyperabsorption has also been confirmed in nasal epithelia of CFTR deficient mice. ${ }^{47}$ With the recent cloning of the rat epithelial amiloride sensitive $\mathrm{Na}^{+}$channel $(\mathrm{rE} \mathrm{NaC})$, pivotal experiments by B oucher and colleagues ${ }^{48}$ have demonstrated that functional CFTR inhibits $\mathrm{Na}^{+}$ absorption through this amiloride sensitive pathway. $O$ ther reports have since confirmed these findings and suggested that CFTR probably interacts with $\mathrm{ENaC}$ through either indirect or direct mechanisms. ${ }^{49,50}$ Such evidence suggests that in addition to serving as an apical membrane chloride channel, CFTR may play a broader role in regulating electrolyte transport in the airway through interactions with sodium channels. A dditionally, evidence from intact bronchial CF and non-CF xenograft airways suggests that CFTR may also regulate non-amiloride sensitive $\mathrm{Na}^{+}$channels. ${ }^{51}$ Together, these findings which suggest that CFTR regulates $\mathrm{Na}^{+}$conductance pathways have implications for the mechanisms by which CFTR facilitates fluid and electrolyte transport in the airways.

A $n$ additional function of CFTR is its ability to facilitate ATP transport in the regulation of the outwardly rectifying chloride channel (ORCC). ${ }^{52}$ Previous studies have correlated the extent of CFTR facilitated ATP transport with the activation of OR CC mediated chloride conductances, using in vitro reconstitution of CFTR in a CF airway epithelial cell line. ${ }^{53}$ $M$ utational analysis of CFTR, which demonstrated that the CFTR mutant G 551D is defective in A TP facilitated transport, has suggested that this function is at least in part contained within the first nucleotide binding fold of CFTR. The activation of ORCC is thought to occur through ATP binding to $P_{2} U$ receptors and subsequent intracellular signaling through PKC pathways. A Ithough this regulatory function of CFTR is currently highly debated, ${ }^{54}$ several additional laboratories have also noted that CFTR can facilitate ATP transport in a number of cell lines. ${ }^{55-57}$ The added complexity of CFTR as a regulator of ATP transport in the airway has tremendous implications on potential mechanisms of interaction with other channels important in fluid and electrolyte balance.

\section{CFTR as an Intracellular Chloride Channel}

$\mathrm{In}$ addition to serving as an apical membrane chloride channel important in mediated electrolyte transport, CFTR has also been suggested to exist as an intracellular chloride channel within endosomal compartments. CFTR in this region has been proposed to facilitate endosomal acidification by acting as a counter ion pathway for acidification by an ATP-driven proton pump. ${ }^{58-60}$ In CF epithelial cells this defect is proposed to cause a shift in the intravesicular $\mathrm{pH}$ of Golgi compartments, which in turn decreases the activity of modifying enzymes such as sialyltransferase. ${ }^{58-60}$ Such alterations in the activities of glycoprotein modifying enzymes are thought to be the basis of CF associated biochemical defects found in secreted and membranebound glycoproteins, including alterations in sulfation, sialylation, and glycosylation. ${ }^{37,61,62} \mathrm{An}$ alternative hypothesis has recently been proposed by which CFTR functions as a transporter of the sulfate donor adenosine 3'-phosphate 5'-phosphosulfate (PAPS) in Golgi compartments. ${ }^{57}$ This mechanism attempts to explain that the increased sulfation of glycoproteins arises from an increase in the concentration of intravesicular sulfate donors. Previous studies have evaluated the extent of sialylation and sulfation in purified secreted mucin from CF patients, ${ }^{30,31}$ primary tissue explants, ${ }^{35,36}$ and human bronchial xenografts. ${ }^{33,34}$ These studies have demonstrated an increase in the extent of sulfation and a decrease in the level of sialylation within large molecular weight purified mucin samples from CF as compared to non-CF. A dditional evidence supporting the hypothesis that CFTR functions within endosomal membranes stems from studies of endosomal recycling. Such studies have provided evidence that CFTR also plays an important role in regulating exocytosis and endocytosis of subapical vesicular compartments. ${ }^{63-65}$ These findings directly implicate activation of CFTR with increased exocytosis and decreased endocytosis at the apical membrane. In summary, substantial evidence supports the notion that CFTR has important intracellular functions in epithelial cells.

\section{CFTR as a Receptor for P. Aeruginosa in Airway Epithelial Cells}

Recent evidence has suggested that CFTR may also play a role in bacterial clearance from the airway by acting as a receptor for $P$. aeruginosa in airway epithelial cells. ${ }^{66,67}$ Findings from Pier and colleagues suggest that functional CFTR within the apical membrane of epithelial cells specifically binds and internalizes $P$. aeruginosa. Complementation studies using a transformed CF airway epithelial cell line (CFT1) have demonstrated that reconstitution of CFTR function using recombinant retroviruses leads to a substantial increase in the ability of this cell line to internalize bacteria, as compared to the parental ( $\Delta \mathrm{F} 508$ homozygous) or a control cell line infected with $\Delta F 508$ containing retrovirus. Molecular dissection of this 
phenomenon has suggested that the first extracellular loop of CFTR may act as a receptor for P. aeruginosa; since bacterial binding is blocked by antibodies to the first, but not the fourth, extracellular domain of CFTR. ${ }^{68}$ These results, which define $P$. aeruginosa binding to the first extracellular domain of CFTR, implicate bacterial ingestion by airway epithelial cells as a mechanism of bacterial clearance from the airways.

\section{Pathophysiologic Mechanisms of CF Airway Disease}

A s discussed in the previous section, CFTR has been implicated in numerous functions of airway epithelial cells. The most widely studied primary defects associated with CFTR dysfunction have been summarized in Figure 3. These primary defects have in turn been classified into four general categories of pathogenesis

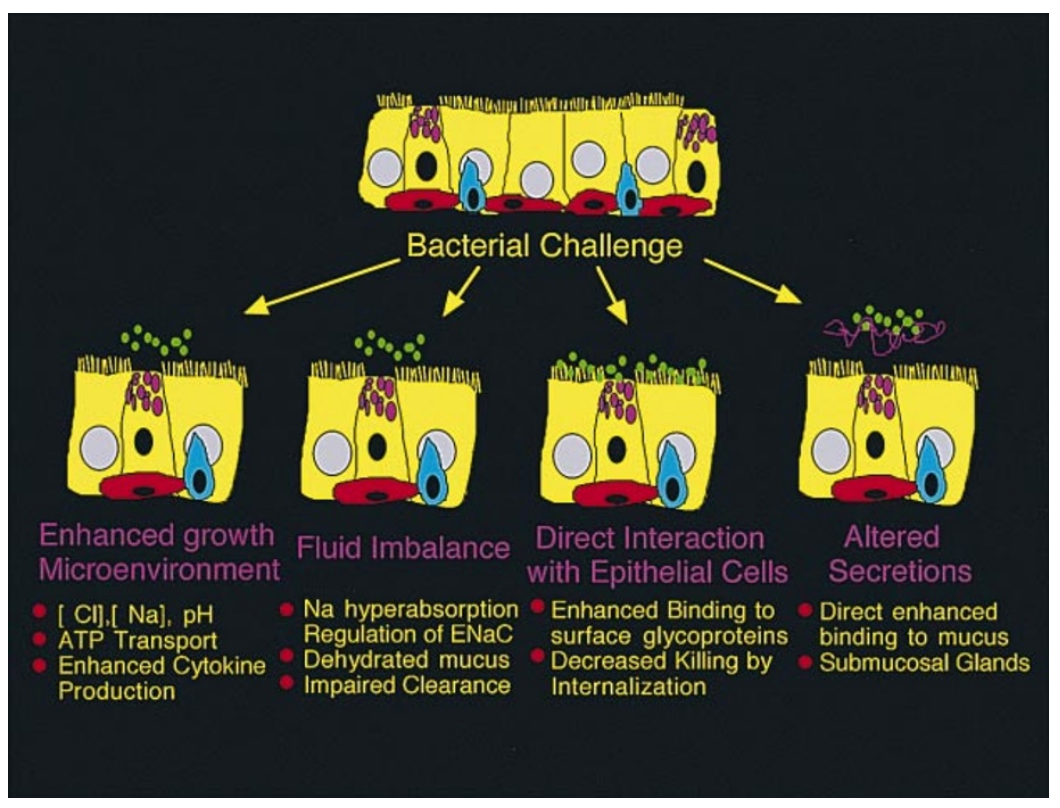

Figure 3 Pathophysiologic mechanisms of bacterial colonization in CF.

Pathophysiologic mechanisms of CF bacterial colonization in the airway have been classified into four general categories including: 1) enhanced growth microenvironment for bacteria at the airway surface, 2) dysregulation of fluid balance in the airway, 3) direct interaction of bacteria with epithelial cells, and 4) altered secretions. Each of these categories has several listed primary defects which have been associated with CFTR dysfunction. E nhanced growth microenvironment: M echanisms of enhance bacterial growth microenvironment include alterations in surface airway fluid salt concentrations which may lead to a decreased activity of antibacterial substances. ${ }^{75,76}$ A dditionally, CFTR -facilitated ATP transport may act to regulate other channels important in homeostasis of surface airway fluid salt concentrations $s^{53}$ and/or may effect bacterial colonization directly by as yet undefined mechanisms. E ffects of bacterial binding to surface airway epithelial cells which lead to dysregulation of proinflammatory cytokine production also fall into this category. Fluid imbalance: D efective CFTR function leading to dysregulation of $E \mathrm{NaC}$ results in sodium hyperabsorption in the airway. ${ }^{48}$ This defect may be the cause of increased fluid absorption seen in CF as compared to nonCF airways. ${ }^{51,72,74} \mathrm{~A}$ lthough the exact mechanism of increased fluid absorption seen in CF airways is debated, such defects have been proposed to lead to dehydrated mucus and impaired mucociliary clearance of bacteria in the airway. Direct interaction with epithelial cells: Two additional mechanisms of bacterial colonization in the airway propose the direct interaction of bacteria with surface epithelial cells. One such mechanism includes enhanced binding of bacteria to biochemically altered surface glycoproteins ${ }^{78,79,81-83}$ as a result of intracellular defects in glycoprotein processing compartmentes of CF cells. ${ }^{58-60} \mathrm{~A}$ second mechanism proposes that CFTR itself may serve as a receptor for P. aeruginosa and play a role in bacterial clearance from the airway. This mechanism of bacterial clearance has been suggested to be defective in C F ${ }^{66-68} \mathrm{~A}$ Itered secretions: Secretory proteins in the airway predominantly come from two sources, goblet cells within the surface airway epithelium and submucosal glands. $D$ efects in the biochemical properties of secreted mucin have been demonstrated in $C F^{30-35}$ and likely occur as a result of defective intracellular functions of CFTR in glycoprotein processing compartments. ${ }^{58-60}$ These defects may lead to altered properties of bacterial binding and colonization which enhance the susceptibility of CF airways to infection. ${ }^{79,80}$ Submucosal glands which express high levels of CFTR and secrete a number of antibacterial proteins may also play an important role in protection of the airways. D efective CFTR in this region has been proposed to decrease secretions from submucosal glands due to impaired salt and fluid transport by serous cells. 
including: 1) enhanced growth microenvironment for bacteria, 2) fluid imbalance, 3) direct interactions with epithelial cells, and 4) altered secretions. E ach of these categories of primary defects proposes unique pathophysiologic mechanisms with different implications in the design of gene therapy strategies to correct bacterial colonization defects in CF. This section will attempt to outline the current understanding of these mechanisms of CFTR dysfunction and the implications for CF airways pathogenesis. Of importance is the determination of which CFTR associated functional phenomena are most relevant from a pathophysiologic standpoint. Such a foundation will be necessary to interpret the limitations and concerns associated with strategies to correct these defects by gene targeting.

\section{Altered Fluid Balance and Decreased Bacterial Clearance (Na Hyperabsorption Model)}

The etiology of CF airway disease has been traditionally viewed to center around dehydrated mucus and poor mucociliary clearance. The present understanding of CF airways pathogenesis has suggested that decreased airway surface liquid may in part, but not completely, explain observations seen in CF-associated lung disease. ${ }^{69-71}$ The most widely associated defect thought to be responsible for dehydration of the airways in $\mathrm{CF}$ is $\mathrm{Na}$ hyperabsorption. As discussed above, defective regulation of ENaC by CFTR is thought to be the underlying mechanism for this phenomenon. Several laboratories have investigated the rate of fluid transport in models of polarized CF and non-CF airway epithelia. In these studies, correlation of electrolyte and fluid transport using in vitro polarized nasal monolayers supported the notion that absorptive $\mathrm{Na}^{+}$conductance is a primary driving force of fluid absorption in airway epithelium, while stimulation of $\mathrm{Cl}^{-}$secretion drives fluid secretion. ${ }^{72-74} \mathrm{~A}$ dditionally, in vivo studies using a human bronchial xenograft model have demonstrated a fourfold higher rate of fluid absorption in CF as compared to non-CF airways under basal conditions. ${ }^{51}$ Together these in vitro and in vivo findings suggest a mechanism by which increased fluid absorption in CF airway epithelia leads to dehydration of mucus and impaired mucociliary clearance. Such an impaired clearance is hypothesized to lead to an increased bacterial burden in the lungs of CF patients. Of importance is a better understanding of the mechanism(s) by which polarized airway epithelia regulate the composition and volume of surface airway fluid. These mechanisms are currently a source of wide debate in the field. For example, based on findings which suggest that CF surface airway fluid is hypertonic in comparison to non-CF, one would predict that the airway may be relatively impermeable to $\mathrm{Cl}^{-}$as a result of CFTR dysfunction. These findings are inconsistent with the notion that CF airways actively hyperabsorb $\mathrm{Na}$ and passively absorb $\mathrm{Cl}^{-}$(through pericellular pathways) in the movement of salt and water out of the airways. Such discrepancies highlight the present lack of knowledge concerning mechanisms of salt and fluid transport in the airways.

\section{Decreased Bactericidal Activity of CF Surface Airway Fluid}

A Ithough the exact mechanism(s) by which airways regulate fluid and electrolyte balance at their surface is unknown, recent studies demonstrating reduced bactericidal activity of CF airway secretions have suggested that alterations in the $\mathrm{NaCl}$ concentration of $\mathrm{CF}$ surface airway liquid may create a favorable milieu for bacterial colonization. ${ }^{75}$ Such studies have correlated increases in CF airway liquid salt concentration with decreased bacterial killing activity of surface airway fluid. These findings have led to an emphasis of study in the field focused on characterizing the properties of antibacterial substances in the airway. To this end, the gene encoding the human antibacterial peptide, $\beta$-defensin, has been cloned and demonstrated to be expressed at high levels in surface airway and submucosal gland epithelia by in situ hybridization. ${ }^{76,77}$ Furthermore, the synthesized $\beta$-defensin peptide demonstrates a salt-sensitive bacterial killing activity. ${ }^{76}$ Functionally, this gene has been implicated in antibacterial properties of surface airway fluid, as demonstrated by the ability of antisense oligonucleotides to decrease both the level of gene expression and the bactericidal activity of the surface airway fluid. ${ }^{76}$

\section{Increased Bacterial Binding to Biochemically Altered Glycoproteins in CF Airways}

N umerous laboratories have suggested that alteration in CF glycoprotein processing may lead to increased bacterial adhesion to airway epithelial cells. To this end, defects leading to increases in the abundance of asialoG M 1 in surface glycoproteins have been demonstrated to increase the binding of $P$. aeruginosa by $3-4$ fold in CF airway epithelial cells. ${ }^{78-83} \mathrm{H}$ owever, since differences in binding are small, the relevance of these findings to disease pathogenesis in CF remains to be proven. R esearchers have speculated that such small 
differences in bacterial binding may be important in signaling CF airway epithelia to produce pro-inflammatory cytokines such as IL -8 , which might catalyze an inflammatory cascade promoting the production of yet more pro-inflammatory cytokines in the airway. ${ }^{84}$ This dysregulation of anti- and pro-inflammatory cytokines may in part play a role in the altered immune responses seen in $C F .{ }^{85,86}$ Furthermore, analyses of bronchioalveolar lavages from CF infants have suggested that dysregulation of pro-inflammatory cytokines may occur very early in the onset of airways disease. ${ }^{87,88} \mathrm{U}$ nder these conditions it is plausible that small increases in bacterial binding could be an inciting event which triggers recurrent infections through pro-inflammatory signals. The contribution of altered properties of secreted mucin to bacterial pathogenesis in CF airways is less understood. However, bacterial binding to secreted airway mucin has been observed ${ }^{80}$ and may provide an altered milieu which is conducive to colonization in CF. Furthermore, changes associated with the mucoid conversion of Pseudomonas suggest that interactive signals from the airway environment (perhaps from mucins) may promote transcriptional changes in the bacterial genome necessary for persistence.

\section{Decreased Bacterial Clearance due to Defective CFTR-Mediated Bacterial Uptake}

Perhaps the most widely debated yet intriguing phenomena proposed as a mechanism of CF airways pathogenesis, are the findings which suggest that CFTR acts as a receptor for bacterial uptake and clearance by airway epithelial cells. Studies have associated mutant CFTR $(\Delta 508 \mathrm{~F})$ with decreased bacterial uptake using in vitro model systems. ${ }^{67,68}$ Since binding appears to be specific for P seudomonas, such findings may explain the unique hypersusceptibility of CF lungs to bacterial infection with this strain of bacteria. However, the magnitude to which this phenomenon contributes to the protection of lungs in humans is unclear. N onetheless, defective low level clearance of bacteria by CFTR could play a critical role in initiating the cascade of infection during early events of colonization in CF.

\section{Submucosal Gland Involvement in Maintaining Antibacterial Properties of the Airway}

Submucosal glands are a predominant site of CFTR expression in the proximal airway. ${ }^{24,26,89,90}$ This finding has led to interest in determining whether submucosal glands contribute to the pathoprogression of CF airway disease. Several experimental observations have suggested that submucosal glands may be adversely affected in CF. First, abnormalities of submucosal gland duct swelling have been noted in post-mortem tissues from fetal and newborn CF patients. ${ }^{91}$ These data have suggested that submucosal gland function may be affected very early, before the onset of apparent disease. Second, submucosal glands suffer from severe hypertrophy in CF patients with chronic airways disease. Unlike the findings of gland duct swelling in fetal airways, gland hypertrophy in late stage airways disease is likely to be secondary to chronic bacterial infection. Nonetheless, morphologic evidence for submucosal gland abnormalities exists both early and later during CF pulmonary diseases. A dditionally, the abundance of CFTR-expressing cell types in gland ducts appears to be altered in cystic fibrosis; the frequency of this cell type increases as much as 40 fold within submucosal glands of CF bronchial tissue. ${ }^{24}$ Such effects support the notion that CFTR in this region is important for submucosal gland function. Serous cells, which also express high levels of CFTR in submucosal glands, are responsible for secreting a mixture of antibacterial proteins (ie lysozyme, lactoferrin, and phosphatases) which may be important in the protection of the airway from diseases ${ }^{93,94} \mathrm{H}$ ence, given the fact that submucosal glands express abundant CFTR protein and these regions also secrete antibacterial proteins, a hypothesis has emerged that defective CFTR in serous cells may lead to hindered fluid secretion from glands and hence decreased antibacterial secretions at the airway surface. The importance of this region in regulating airway fluid and electrolyte composition in the airways should also be underscored. Given the recent evidence that altered airway salt concentrations in CF may lead to a decreased bactericidal activity of airway secretions, a renewed interest in the mechanisms by which submucosal glands contribute to the regulation of airway salt concentrations has also emerged.

\section{Models of Cellular Compartmentalized $\mathrm{Na}^{+}$and $\mathrm{Cl}^{-}$ Transport in Electrically-Tight Epithelia}

Both $\mathrm{Na}^{+}$and $\mathrm{Cl}^{-}$transport abnormalities are at the foundation of primary CF defects associated with 
dysregulated surface airway fluid volume and electrolyte composition. To rationally develop therapeutic strategies directed at correction of these defects, a firm understanding of the mechanisms which control airway fluid and electrolyte movement is imperative. As discussed above, the heterogeneous patterns of CFTR expression in the airway suggest that these mechanisms may include a complex interplay of multiple cellular compartments which regulate CFTR-mediated $\mathrm{Cl}^{-}$ secretion and absorption. A dditionally, since CFTR has been demonstrated to regulate a number of other apical membrane channels involved in both $\mathrm{Na}^{+}$and $\mathrm{Cl}^{-}$transport, an added level of complexity includes the distribution of these CFTR-regulated channels in the various cellular compartments which control ion flow. Comparisons to other electrically tight epithelial model systems have provided useful information on which to build hypotheses regarding mechanisms of electrolyte and fluid transport in the airways.

A mphibian epidermis is one such model system which draws striking similarity to the airway with regard to cellular compartmentalization of $\mathrm{Na}^{+}$and $\mathrm{Cl}^{-}$ transport. $^{95}$ In frog skin, mitochondrial rich cells composing approximately $1 \%$ of the cells in this epithelial layer account for the entire chloride conductance and bicarbonate/acid secretion. Interestingly, the route of transepithelial chloride fluxes in the amphibian skin through mitochondrial rich cells also appears to be controlled by a $3^{\prime}-5^{\prime}$ cyclic monophosphate (CAMP)-dependent pathway. ${ }^{95,96}$ The relevance of these findings to CFTR function in amphibian mitochondrial rich cells is presently unclear. However, immunocytochemical localization studies in amphibian epidermis using human anti-CFTR antibodies has demonstrated high level apical CFTR protein expression in a cell type of similar abundance and location to that of mitochondrial rich cells (Figure 4). The intense electrophysiologic characterization of this amphibian epidermal model has conclusively demonstrated that $\mathrm{Cl}^{-}$and $\mathrm{Na}^{+}$conductance pathways are through distinct cellular populations $\mathrm{Na}^{+}$absorption through the majority of epidermal cells and $\mathrm{Cl}^{-}$absorption through the subset of mitochondrial rich cells). The similarities between amphibian epidermal, surface airway, and submucosal glandular epithelia with respect to highly regulated CFTR expression is intriguing and suggests that similar mechanisms of regulating ion conductances may exist between these model systems. Such a hypothesis for cell-type specific regulation of $\mathrm{Na}^{+}$and $\mathrm{Cl}^{-}$conductance in bovine tracheal epithelium has been previously suggested ${ }^{97,98}$ and is highlighted in Figure $2 c$. If this hypothesis is true, gene targeting to correct
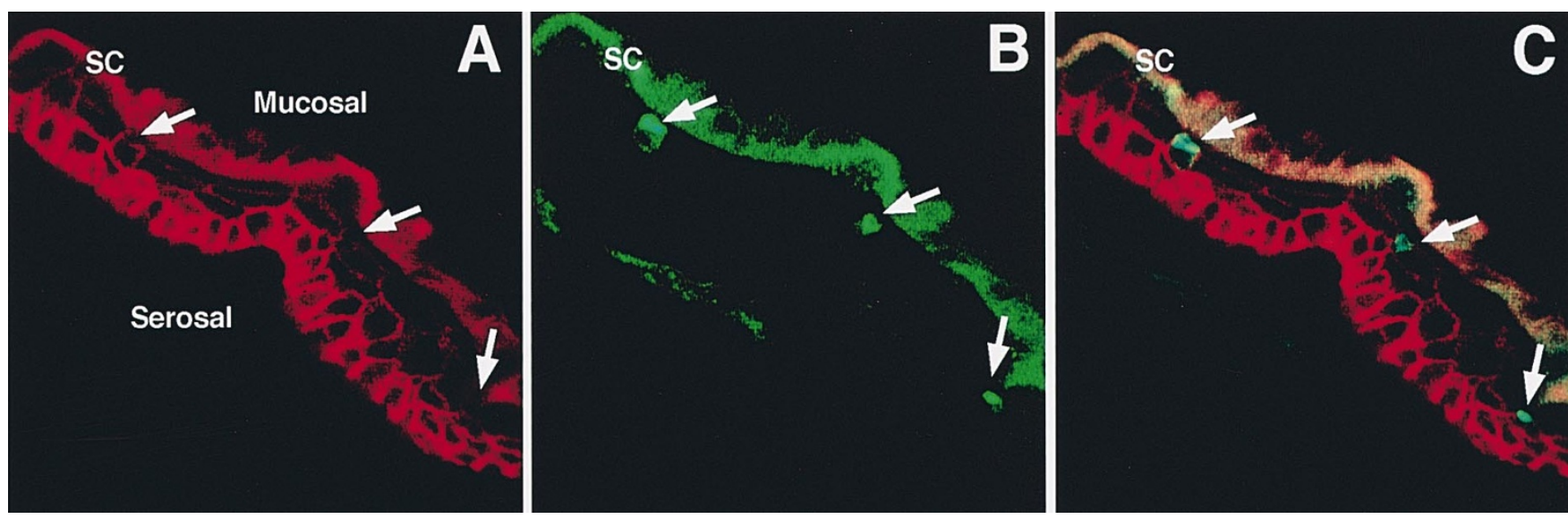

Figure 4 H eterogeneous expression of CFTR in amphibian epidermis.

I mmunocytochemical co-localization of CFTR and $\mathrm{Na}^{+} / \mathrm{K}^{+}-\mathrm{ATP}$ ase was performed on B ufo bufo epidermis using an anti-human $\mathrm{C}$-terminal CFTR polyclonal antibody and a monoclonal antibody to $\mathrm{Na}^{+} / \mathrm{K}^{+}-\mathrm{ATP}$ ase. Immunoreactive proteins were visualized by confocal microscopy with FITC (CFTR) and Texas-R ed ( $\mathrm{Na}^{+} / \mathrm{K}^{+}$-ATPase) secondary antibodies. Panel A depicts the Texas-R ed channel which localizes $\mathrm{Na}^{+} / \mathrm{K}^{+}$-A TPase at high levels to basolateral surfaces of epithelial cells in the lower half of the epidermis (serosal side). Panel B depicts the FITC channel which localizes high levels of CFTR immunoreactivity to a subset of cells (arrows) at the lumenal face (mucosal side) of the epidermis. The combined image of both FITC and Texas-R ed channels are given in Panel C. The stratum corneum (SC) exhibits autofluorescence in both Texas-R ed and FITC channels does not represent immunoreactivity as demonstrated by a similar pattern of fluorescence in unstained tissue sections (data not shown). This autofluorescence of the stratum corneum appears yellow in Panel C. The frequency and location of CFTR immunoreactivity is consistent with staining in mitochondrial rich cells. This heterogeneous pattern of CFTR staining may explain the cellular partitioning of chloride and sodium transport in amphibian skin. Such models set the stage for understanding the link between heterogeneous patterns of CFTR expression and function in regulating electrolyte and fluid balance in the airway. 
chloride secretory defects may encompass different cell types than those necessary to achieve correction of $\mathrm{Na}^{+}$ absorption defects.

\section{Challenges for Gene Therapy of CF Lung Disease}

The heterogeneity of CFTR expression and function in the lung has posed several significant obstacles to the design of gene therapy strategies for CF airways disease. To this end, several pertinent questions have emerged: 1) Will targeting to surface airway epithelium be sufficient or will gene transfer to submucosal glands also be required? 2) Since CFTR is expressed at widely different levels in functionally distinct cellular populations in the airway, will regulated gene expression be necessary to restore endogenous functions of CFTR ? and 3) Of the numerous cellular targets which express CFTR, which are pathophysiologically most relevant from the standpoint of correcting chronic bacterial infection?

\section{Submucosal Glands vs. Surface Airway Epithelium}

The question as to whether submucosal glands are important targets in CF airway disease will probably need to await the development of appropriate animal models to test this hypothesis. CFTR-deficient mouse models have proven useful in studies of nasal epithelia and in fact may represent the only in vivo model at present by which to evaluate CFTR dependent nasal submucosal gland function in protection of the airways. However, unlike humans, glands are not located throughout the cartilaginous airways of mice and hence they are inadequate models for addressing whole lung CF pathophysiology as it pertains to gland function. The potential development of alternative animal models such as the ferret, for which gland structure and abundance in the lung is similar to that of humans, may in time fill this void. ${ }^{99}$ If submucosal glands are important targets for gene therapy of CF, several gene delivery methods have been proposed to target this region which is inaccessible from the airway. 0 ne such delivery system has utilized the polymeric I gA receptor to target D NA/protein complexes through the blood to glandular cells. ${ }^{100,101}$ Since polymeric IgA is transcytosed across the basement membrane of epithelial cells in the lung, this methodology poses several theoretical advantages for gene targeting to airway glands in the adult lung. A second approach has proposed to utilize gene targeting to gland stem cell in the fetal surface airway epithelium prior to gland development. This approach has proven successful in newborn ferret ${ }^{102}$ and regenerating human ${ }^{103}$ airway xenograft models using recombinant retroviruses. Since gene targeting occurs prior to subsequent expansion of progenitor cells in the formation of glands, retroviruses are attractive vehicles since they integrate their transgenes. H owever, due to limitations in titer of retroviral stocks, applications for in vivo delivery in humans may require the use of an alternative vehicle such as recombinant adeno-associated virus which can be generated at much higher titers and also has the capacity for integration.

\section{Functionally Distinct CFTR-Expressing Cellular Compartments in the Surface Airway Epithelium}

The concept of functionally diverse CFTR-expressing cellular population in the airway is now only beginning to be appreciated. U nfortunately, in the field of CF, the literature is plagued with the concept that CFTR functions uniformly within all airway epithelial cell types. In part, this shortcoming may be the cause of debate in some areas with regard to model system dependency of CFTR -associated functions. This has led to a re-evaluation of what model systems are adequate for assessing CFTR function and complementation. $M$ odel systems utilizing genetically defined human CF and non-CF polarized primary cells in culture or in xenografts may prove to be the best models at present. $N$ onetheless, several hypotheses can be generated with respect to the diversity of CFTR expression in the airway and potential compartmentalization of CFTR functions, which pose significant challenges to the treatment of this disease by gene targeting approaches. For example, the recent identification of CFTR regulatory effects on $\mathrm{ENaC}^{48}$ has suggested that co-expression of these two channels in certain cell types may be critical in the control of airway fluid composition. Since sodium absorption is thought to be the driving force for fluid reabsorption in the airway, ${ }^{104,105}$ cell types expressing both CFTR and ENaC may be critical targets in CF gene therapy. Such a hypothesis demonstrating low levels of CFTR expression in ciliated cells which express $\mathrm{ENaC}$ is schematically drawn in Figure 2c. E vidence for ubiquitous expression of $\mathrm{EN} \mathrm{aC}$ subunits has demonstrated that this channel is abundantly expressed in the airway superficial and glandular epithelium and implicated expression in ciliated cells. ${ }^{106,107}$ Although immunocytochemical 
localization studies have not yet been performed in the lung, other electrolyte transporting epithelial tissues such as the colon and sweat duct demonstrate uniform protein expression in superficial epithelium. ${ }^{108,109}$ These studies substantiate the hypothesis that $\mathrm{ENaC}$ is an abundantly expressed channel in absorptive and secretory epithelia. From a gene therapy standpoint, the low level of CFTR expression in ciliated cells of the airway may be important in coordinating interactions with $\mathrm{ENaC}$ in the regulation of fluid balance.

A second cell type of interest in the airway is a nonciliated cell which expresses extremely high levels of CFTR and is found only infrequently (1-3\%) in the surface airway and submucosal gland ducts. ${ }^{24}$ One can speculate that this non-ciliated, CFTR-expressing columnar cell type might serve an alternative function to CFTR-expressing ciliated cells, since the level of CFTR is much higher. Furthermore, given the infrequent nature of this cell type and the present lack of immunocytochemical co-localization data, it is unknown whether $\mathrm{ENaC}$ is expressed in this population of cells which highly expresses CFTR. The model proposed in Figure $2 c$ suggests that this cell type may be similar to the mitochondrial rich 'flask-like' cell found in amphibian skin, which is responsible for all chloride transport in this cellular heterogeneous epidermal layer. This model suggests that CFTR may act as a 'cellular faucet' to transport high levels of chloride (and/or perhaps $\mathrm{HCO}_{3}$ ) across the epithelium. Such a cell type may play an important role in fine tuning the concentration of salt and fluid in the airway. The function of this particular cell type in airway fluid and electrolyte homeostasis is extremely important from a gene therapy standpoint. For example, in the absence of cell-specific targeting, current gene transfer protocols would probably need to transduce all airway epithelial cells to target CFTR transgene to this infrequent population of cells. The central underlying question in this regard is whether gene targeting to this cell type will be necessary to correct the CF abnormalities in fluid and electrolyte transport.

A third cellular population, goblet cells, which appears to express CFTR at very low levels by functional criteria evaluating glycoprotein processing defects in $C F$, also presents challenges from the standpoint of gene targeting. O ne questions whether the level of CFTR expression in these cell types may also need to be properly regulated to achieve normal glycoprotein modification in $\mathrm{G}$ olgi compartments. Furthermore, if defects in glycoprotein modification are pathophysiologically significant, the abundance of goblet cells would also require substantially higher transfection efficiencies to achieve complementation with non-targeted vectors.

\section{Distinct Primary Defects in CF Airway Epithelia have Unique and Diverse Complementation Profiles}

Several lines of evidence studying the complementation profile of CF associated transport defects in polarized epithelia and human bronchial xenografts have shed light on the above obstacles for gene therapy. E vidence by Boucher and colleagues have demonstrated that only $5-10 \%$ gene transfer, using CFTR recombinant retrovirus, is necessary to achieve complete correction of transepithelial chloride secretory defects in CF epithelial monolayers ${ }^{110}$ (Figure 5a). These investigators hypothesize that airway epithelial cells within polarized monolayers are electrically linked through gap junctions which can cooperatively pass chloride across the epithelium (Figure $5 b$ ). These findings have been confirmed in other model systems such as the human bronchial xenograft utilizing recombinant adenovirus for complementation. ${ }^{111}$ Such studies which have overexpressed wtCFTR in a subpopulation of CF cells, partially resembles the pattern of CFTR expression in the normal airway. The fact that chloride secretion can be fully corrected at this level of transgene expression supports the notion that the infrequent non-ciliated columnar cell expressing high levels of CFTR in the endogenous airway may act as a 'chloride faucet' in the control of airway $\mathrm{Cl}^{-}$permeability (Figure 2C). Furthermore, this model argues that the level of CFTR expression alone (and not the composite of other channels in this cell type) may dictate cellular involvement in functions of transepithelial chloride secretion.

In contrast, $\mathrm{CF}$ defects in $\mathrm{Na}^{+}$hyperabsorption have required higher levels of CFTR gene transfer to correct the dysregulation of $\mathrm{ENaC}^{111,112}$ since all cell types which express $\mathrm{ENaC}$ must be targeted to achieve complete correction (Figure $5 a$ and $5 b$ ). Furthermore, the high percentage of gene transfer necessary to achieve functional correction of $\mathrm{Na}^{+}$hyperabsorption defects in CF epithelia, together with the fact that $\mathrm{ENaC} \mathrm{mRNA}$ is expressed in virtually all or most cell types in the airway, suggest that ciliated cells are, at least in part, targets for correction of this defect. Such findings also support a hypothesis of compartmentalized CFTR functions as presented in Figure 2c. In 

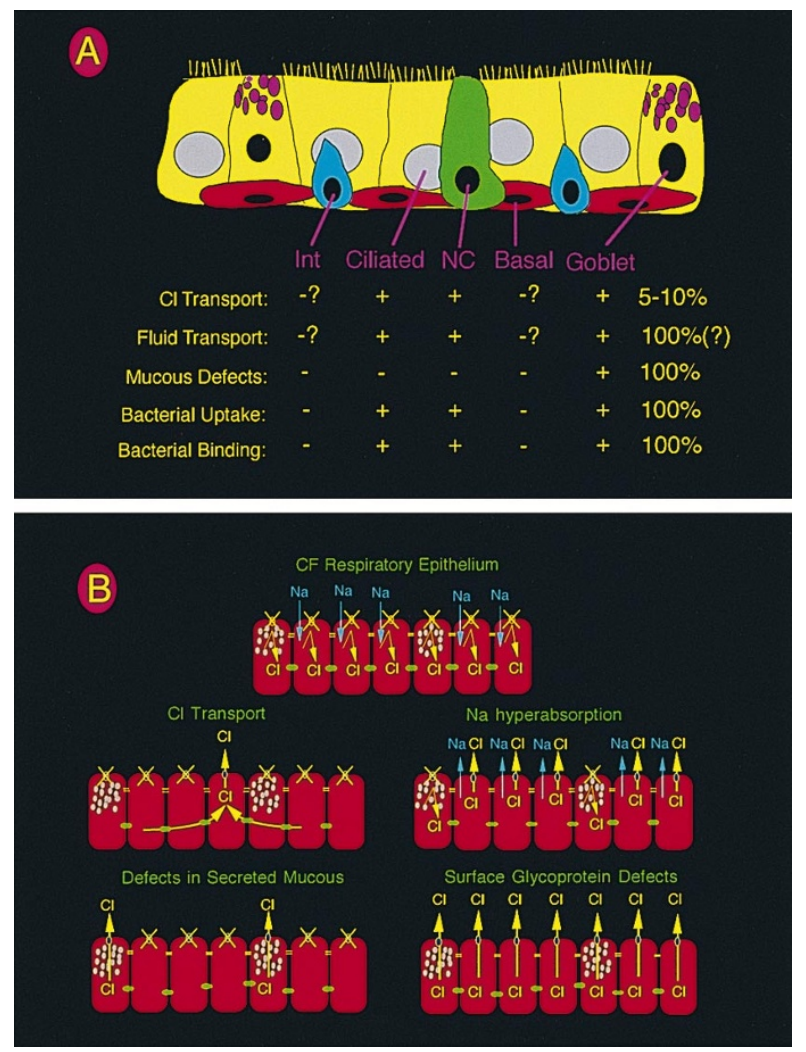

Figure 5 Diversity of complementation profiles for gene therapy of primary defects in CF airway epithelia.

The cellular targets for complementation of five CF associated primary defects are given in Panel A. The total percentage of gene transfer to these cellular targets needed for full correction of these primary defects is noted in the right margin. For example, to completely reverse intracellular glycoprotein processing defects in CF secreted mucin, it will be necessary to target $100 \%$ of goblet cells. In Panel B, the complementation profile of four distinct primary defects are schematically depicted for 1) $\mathrm{Cl}^{-}$transport, 2) $\mathrm{Na}^{+}$hyperabsorption, 3) glycoprotein processing defects in secreted mucin, and 4) surface glycoprotein defects which promote bacterial binding. Complementation of $\mathrm{Cl}^{-}$secretory defects requires as little as $5-10 \%$ correction due to intercellular communication through gap junctions. ${ }^{110}$ In contrast, correction of $\mathrm{Na}^{+}$hyperabsorption defects requires targeting of those cell types which co-express E NaC and CFTR (likely to include ciliated cells). The level of gene transfer needed to correct defects of $\mathrm{Na}^{+}$hyperabsorption is significantly greater than that for $\mathrm{Cl}^{-}$secretion. ${ }^{111}$ Complementation of biochemical defects in secreted mucin requires targeting of goblet cells to correct intracellular functions of CFTR. In the absence of vectors which have the ability to specifically target goblet cells, the percentage of gene transfer necessary to completely correct abnormalities in secreted mucin likely approach $100 \%$ of the epithelium. ${ }^{34}$ Similarly, complementation of surface glycoprotein defects which lead to decreased sialylation in CF will require targeting of all cell types which reach the lumenal face of the airway to correct abnormalities in bacterial binding. summary, studies utilizing recombinant adenoviral and retroviral mediated gene transfer to CF epithelia support the notion that primary defects in $\mathrm{Cl}^{-}$secretion and $\mathrm{Na}^{+}$hyperabsorption have drastically different complementation profiles.

Similarly, studies evaluating complementation of mucous sulfation defects in human CF bronchial xenografts have demonstrated that gene targeting with CFTR recombinant adenoviruses requires levels of gene transfer approaching $100 \%$ of airway cells to reverse sulfation defects ${ }^{34}$ (Figure 5a). This is contrasted to the $5-10 \%$ infection needed with this same vector to complement chloride secretory defects as measured by transepithelial potential difference. ${ }^{34,111}$ H owever, in these studies, complementation of mucous sulfation defects could be achieved with less efficient vectors such as CFTR cDNA/liposome complexes which are capable of delivering low levels of transgene expression to a larger target population of cells. While liposome gene transfer was efficient in correcting mucous sulfation defects, it did not efficiently correct chloride transport defects. These vector-specific complementation profiles underscore the need for understanding both the mechanism of vector-mediated gene transfer and expression, as well as the molecular basis of the functional defects being used to assess complementation. For example, to achieve complete complementation of mucous sulfation defects, gene targeting must be achieved in all goblet cells (Figure 5a and 5b). H owever, only a small amount of functional CFTR in the Golgi compartment of goblet cells (similar to that seen endogenously) appears to be necessary to regulate intravesicular $\mathrm{pH}$ and achieve proper glycoprotein processing following liposome mediated CFTR gene transfer. In contrast, with a single infection of recombinant adenovirus, which delivers a high level of transgene expression to a minority of cells (less than $10 \%$ ) in the airway, correction of chloride secretory defects could be achieved in the absence of complementation for mucous sulfation defects. ${ }^{34,111}$ D ifferences in the complementation profile of these two vectors in correcting $\mathrm{Cl}^{-}$permeability and mucous sulfation defects mirror the ability of recombinant adenovirus and liposomes to reconstitute only certain features of the endogenous distribution and abundance of CFTR protein expression. Such findings highlight the diversity of cellular targets for gene therapy of $\mathrm{CF}$ and the different requirements for correction based on the amount of CFTR protein necessary to achieve normal function. 


\section{Vectors for Gene Therapy to the Airway}

Numerous vector systems have been used to target transgene expression to cells of the lung, including recombinant adenovirus, adeno-associated virus, retrovirus, and liposomes. ${ }^{113-118} \mathrm{M}$ any of these vector systems have been evaluated in numerous animal models, including mice, ${ }^{119-123}$ rats, $^{124-128}$ human bronchial xenografts. ${ }^{34,76,102,103,111,129}$ rabbits $^{130}$ and non-human primates. $^{127,131-135}$ The largest obstacle in evaluating the ability of various gene transfer systems to reverse CF airway pathophysiology is the lack of an animal model reconstituting the pathoprogression of CF lung disease. Although genetically defined CFTR deficient mice have been useful for evaluating nasal epithlial defects in electrolyte transport, analogous studies evaluating lung pathophysiology have been disappointing due the differences in the cell biology between mouse and human lungs. The human bronchial xenograft model has been useful for evaluating specific cellular defects found in the CF airway, however, this model systems also lacks immune responses and whole lung physiology. Despite the lack of an intact animal model of the CF lung, studies of gene therapy to the lung have demonstrated considerable promise in the development of strategies by which to target airway epithelial cells.

\section{Recombinant Adenovirus}

R ecombinant adenoviruses have been the most extensively studied vehicles for gene transfer to the lung. These vectors, which consist of a double stranded, linear $36 \mathrm{~kb}$ DNA genome, have the attractive advantage of high attainable titers together with their ability to infect non-dividing cells. ${ }^{136}$ D espite initial successes of achieving high level gene transfer throughout the mouse $^{119,120}$ and cotton rat airways, ${ }^{124-127}$ studies have suggested that these vectors may be less tropic for fully differentiated human airways ${ }^{137}$ and require high doses of virus to achieve therapeutic levels of infection. ${ }^{129}$ R ecent advances in the biology of vector-epithelial cell interactions have suggested that the abundance of apical surface integrins ( $\alpha \mathrm{V} \beta 5)$ may in part influence the efficiency of recombinant adenoviral gene transfer to human airways. ${ }^{138,139}$ Several studies have demonstrated much higher levels of adenoviral transduction following injury to human and mouse nasal airways, which may alter the expression patterns of these integrins. ${ }^{137,139,140} \mathrm{~A}$ second limitation of current recombinant adenoviral vectors is limited persistence in immune competent animal models due to vector associated cellular and humoral immune responses. ${ }^{119,121,126,141}$ Such immunologic responses are the result of residual viral gene expression and proteins associated with viral particle inoculum. Despite the relatively inefficient infection of fully differentiated human proximal airways with recombinant adenovirus, the ability to use high viral titers for infections may circumvent this limitation, if associated toxicity and inflammation can be abrogated by increasing the safety of vector design. Numerous laboratories have focused efforts on altering the vector design of recombinant adenovirus by deleting or mutating viral genes responsible for cellular associated immunity in an effort to increase the achievable dose of vector administration in the absence of toxicity. ${ }^{119,120,126,141} \mathrm{~A}$ Iternative strategies are aimed at altering the host immune responses to allow for higher levels of vector delivery with more prolonged persistence. A dditionally, the recent cloning of the adenoviral receptor for $\mathrm{A} d 2 / \mathrm{A} d 5$ may pave the way for enhancing the level of infection with this recombinant vector. ${ }^{142}$

\section{Recombinant Adeno-associated Virus}

A deno-associated virus (A AV) is a single-stranded DNA parvovirus and represents an alternative vector for gene delivery to the airway. ${ }^{118} A$ ttractive features of this particular parvovirus include its ability to infect non-dividing cells and integrate into the host genome. In contrast to recombinant adenovirus, which persists as an episome, rAAV can persist as either an episome $^{135,143}$ or as an integrated ${ }^{144,145}$ provirus. Wild type $A \mathrm{AV}$ also has the ability to integrate specifically within a defined site on chromosome $19 .{ }^{146} \mathrm{~A}$ Ithough recombinant A AV vectors loose their ability for site specific integration at this loci, research in this area may ultimately enhance the targeting of A AV to specific sites in the cellular genome. Some researchers have had success in using this virus for persistent gene delivery to the airways of rabbits and non-human primates. ${ }^{130,135,147}$ H owever, it is generally accepted that the level of gene expression with AAV in the lung is much less efficient than in other organs such as muscle. ${ }^{148,149}$ L imitations of this vector for gene delivery to the airway appear to be centered around the target cell's ability to convert single stranded DNA A AV genomes to double stranded expressible DNA forms. ${ }^{150,151}$ Viral uptake does not appear to be a limiting factor with this virus. Further investigation into the cellular factors which promote high level rAAV gene expression in organs such as muscle may ultimately enhance the use of this vector 
for the airway by modulating target cells prior to infection.

\section{Recombinant Retrovirus}

$R$ etroviruses which fall into the classification of R NA viruses have attractive advantages as vectors due to their efficient integration. However, the application of these vectors in the airway is limited by the need for cell division to achieve transduction and low achievable titers with this vector. D espite these limitations, several groups have focused efforts on modifying the cell cycle with growth factors as a mechanism for increasing infection in the airways. ${ }^{152}$ A Iternatively, these vectors may prove useful in approaches of in utero gene therapy for CF, where the target cell population is much reduced and cells are normally actively dividing. The principles of in utero applications of these vectors have been tested in sheep ${ }^{153}$ and xenograft ${ }^{102,103,154}$ models.

\section{Liposomes}

Liposome mediated gene transfer to the airway has considerable advantages due to the low level of toxicity. $\mathrm{H}$ owever, limitations include transient low level expression in differentiated airway epithelia. ${ }^{155}$ D espite this apparent limitation, several laboratories have had considerable success using cationic liposome-mediated gene transfer in several animal models including mouse and rat lung. ${ }^{122,123}$

\section{Protein/DNA Complexes}

O ne particular attraction to the use of protein/D NA complexes as a gene transfer vehicle to the airway is the flexibility for cellular targeting. ${ }^{156}$ These complexes, which are usually composed of a cationic polymer such as poly-lysine together with associated ligand molecules for targeting and uptake, have been successfully used in cell line models. A Ithough their in vivo utility has yet to be proven, strategies such as the polymeric IgA receptor to target D NA/protein complexes through the blood to glandular cells appear to hold promise for targeting this difficult region in CF. ${ }^{100,101}$

\section{Summary}

The elucidation of numerous CFTR functions in airway epithelia has had a tremendous impact on potential pathophysiologic mechanisms of CF airway disease. When this functional diversity is superimposed on the heterogeneity of CFTR-expressing cell types in the lung, the resulting picture of how CFTR dysfunction in the lung leads to bacterial infections becomes overwhelmingly complex. To this end, a clear understanding of the pathoprogression of CF lung disease will only emerge from a concrete mechanistic knowledge of how CFTR functions in the normal airway. A s discussed in this review, mechanisms explaining how CFTR normally functions in airway physiology are likely to involve a dynamic interaction of several unique CFTR expressing cellular compartments in the lung. The diversity of functionally distinct CFTR -expressing compartments in the lung has tremendous implications on gene therapy strategies aimed at correcting CF lung disease. Current strategies for CF gene therapy are based on the concept that reversal of disease pathophysiology will be achieved if the CFTR transgene is expressed at equal levels in all the cells in the airway. Given the apparent functional diversity of CFTR expressing cellular targets, this strategy (that more is better) may be an over-simplification. The challenge for gene therapy of CF will be to determine what cellular targets in the airway contribute to the pathoprogression of CF lung disease and how the appropriate vectors can be used to target the required amount of CFTR protein to each of these cellular compartments. Despite these hurdles, gene therapy of cystic fibrosis has quickly become a paradigm for evaluating the safety and efficacy of gene transfer to the lung. To date, numerous phase I clinical trials have been undertaken in an attempt to evaluate initial toxicity and efficacy of gene transfer using vehicles such as liposomes, recombinant adenovirus, and adeno-associated virus. ${ }^{7-20}$ The success of these clinical trials for CF will largely be based on surrogate endpoints for evaluating the extent of functional complementation of primary CF defects. ${ }^{157} \mathrm{M}$ any of these clinical trials have incorporated measures of functional complementation using the surrogate marker of transepithelial potential difference to assess correction of chloride transport defects. However, the relevance of this endpoint as a measure of efficacy for reversing disease pathophysiology (ie chronic bacterial infections) is not clear. To this end, a major emphasis in the field has been to develop alternative surrogate endpoints for evaluating efficacy in CF gene therapy trials. ${ }^{157}$ By bringing together both a better knowledge of CFTR function in the airway and its pathophysiologic involvement in CF lung disease with the molecular mechanisms by which vectors transduce the airway, we can begin to develop the most appropriate vectors to treat the CF lung. 


\section{Acknowledgements}

This work was supported by NIDDK 2R 0147967 (JFE) and the Cystic Fibrosis Foundation (JFE; QJ).

\section{References}

1 Welsh MJ, Tsui L-C, B oat TF, Beaudet A L: Cystic fibrosis. In: Scriver $C L$, B eaudet $A L$, Sly WS, Valle D (eds.). The M etabolic B asis of I nherited D isease. 7th edn. M cG raw-H ill: N ew York, 1995; pp3799-3876.

2 Rommens J $M$ et al: Identification of the cystic fibrosis gene: chromosome walking and jumping. Science 1989; 245: 1059-1065.

3 R iordan J R et al: I dentification of the cystic fibrosis gene: cloning and characterization of complementary DNA. Science 1989 245: 1066-1073.

4 Kerem $B$ et al: Identification of the cystic fibrosis gene: genetic analysis. Science 1989; 245: 1073-1080.

5 Sferra TJ, Collins FS: The molecular biology of cystic fibrosis. (R eview): A nnual Review of M edicine 1993; 44: 133-144.

6 Bye M R, E wig J M , Q uittell L M : C ystic fibrosis. (R eview) $L$ ung 1994; 172 251-270.

$7 O^{\prime} N$ eal WK, Beaudet AL: Somatic gene therapy for cystic fibrosis. H um M olec G enet 1994; 3: 1497-1502.

8 MCLachlan G et al: Laboratory and clinical studies in support of cystic fibrosis gene therapy using pCM VCFTR -D OTA P. G ene Therapy 1996; 3: 1113-1123.

9 Crystal RG et al: Administration of an adenovirus containing the human CFTR CDNA to the respiratory tract of individuals with cystic fibrosis. Nature $\mathrm{G}$ enetics 1994; 8: 42-51.

10 Knowles MRet al: A controlled study of adenoviralvector-mediated gene transfer in the nasal epithelium of patients with cystic fibrosis. N Eng J Med 1995; 333: 823-831.

11 B oucher R C et al: G ene Therapy for cystic fibrosis using E 1-deleted adenovirus: a phase 1 trial in the nasal cavity. Human G ene Therapy 1994; 5: 615-639.

12 Wilson JM et al: Gene therapy of cystic fibrosis lung disease using $\mathrm{E} 1$ deleted adenoviruses: a phase 1 trial. Human Gene Therapy 1994; 5: 501-519.

13 Flotte $T$ et al: A phase 1 study of an adeno-associated virus-CFTR gene vector in adult CF patients with mild lung disease. H uman G ene Therapy 1996; 7: 1145-1159.

14 Caplen NJet al: Gene therapy for cystic fibrosis in humans by liposome-mediated DNA transfer: the production of resources and the regulatory process. (R eview) Gene Therapy 1994; 1(2): 139-147.

15 Sorscher EJ et al: G ene therapy for cystic fibrosis using cationic liposome mediated gene transfer: a phase 1 trial of safety and efficacy in the nasal airway. Human G ene Therapy 1994; 5(10): 1259-1277.

16 Zabner J et al: A denovirus-mediated gene transfer transiently corrects the chloride transport defect in nasal epithelia of patients with cystic fibrosis. Cell 1993; 75: 207-216.
17 Caplen NJ et al: Liposome-mediated CFTR gene transfer to the nasal epithelium of patients with cystic fibrosis. $\mathrm{N}$ at $M$ ed 1995; 1:39-46. (published erratum appears in $\mathrm{N}$ at $M$ ed 1995; 1(3): 272.)

18 Gill DR et al: A placebo-controlled study of liposomemediated gene transfer to the nasal epithelium of patients with cystic fibrosis. Gene Therapy 1997; 4(3): 199-209.

19 Porteous DJ et al: Evidence for safety and efficacy of D OTA P cationic liposome mediated CFTR gene transfer to the nasal epithelium of patients with cystic fibrosis. G ene Therapy 1997; 4: 210-218.

20 B ellon $G$ et al: A erosol administration of a replication defective recombinant adenovirus expressing normal human CDNA-CFTR in the respiratory tractus in patients with cystic fibrosis. C R Seances Soc Biol Fil 1996; 190(1): 109-142 (in French).

21 Trapnell BC et al: Expression of the cystic fibrosis transmembrane conductance regulator gene in the respiratory tract of normal individuals and individuals with cystic fibrosis. Proc Nat Acad Sci USA 1991; 88: 6565-6569.

22 Chu CS et al: Extensive posttranscriptional deletion of the coding sequences for part of nucleotide-binding fold 1 in respiratory epithelial mR NA transcripts of the cystic fibrosis transmembrane conductance regulator gene is not associated with the clinical manifestations of cystic fibrosis. J Clin Inv 1992; 90(3): 785-790.

23 Rave-Harel $\mathrm{N}$ et al: The molecular basis of partial penetrance of splicing mutations in cystic fibrosis. A m J H um G en 1997; 60(1): 87-94.

24 Engelhardt JF et al: Submucosal glands are the predominant site of CFTR expression in the human bronchus. Nat G enet 1992; 2: 240-248.

25 Trezise $A E, B$ uchwald $M$ : In vivo cell-specific expression of the cystic fibrosis transmembrane conductive regulator.N ature 1991; 353(6343): 434-437.

26 Jacquot Jet al: L ocalization of the cystic fibrosis transmembrane conductance regulator in airway secretory glands. E ur Respir J 1993; 6(2): 169-176.

27 Engelhardt J $F$ et al: Expression of the cystic fibrosis gene adult human lung. J Clin Inv 1994; 90: 2598-2607.

28 Cotton CU et al: A bnormal apical cell membrane in cystic fibrosis respiratory epithelium. A $n$ in vitro electrophysiologic analysis. J Clin Inv 1987; 79(1): 80-85.

29 Kunzelmann K, Kathofer S, Greger $\mathrm{R}: \mathrm{Na}^{+}$and $\mathrm{Cl}^{-}$ conductances in airway epithelial cells: increased $\mathrm{Na}^{+}$ conductance in cystic fibrosis. P flugers A rch E ur J Physio 1995; 431: 1-9.

30 Boat TF, Cheng PW: Biochemistry of airway mucus secretions. Federation Proceedings 1980; 39: 3067-3074.

31 Boat TF et al: Human respiratory tract secretions: mucous glycoproteins of nonpurulent tracheobronchial secretions, and sputum of patients with bronchitis and cystic fibrosis. A rchives of B iochemistry and Biophysics 1976; 177: 95-104.

32 R oussel $P$ et al: $H$ eterogeneity of the carbohydrate chains of sulfated bronchial glycoproteins isolated from a patient suffering from cystic fibrosis. J Biol Chem 1975; 250: 2114-2122.

33 Zhang Y, Doranz B, Yankaskas JR, Engelhardt JF: $G$ enotypic analysis of respiratory mucous sulfation defects in cystic fibrosis. J Clin Inv 1995; 96: 2997-3004. 
34 Zhang $Y$ et al: Vector specific complementation profiles of two independent primary defects in cystic fibrosis airways. (In Press)

35 Cheng PW, Sherman J M, B oat TF, Bruce M : Q uantitation of radiolabeled mucous glycoproteins secreted by tracheal explants. A nalytical B iochemistry 1981; 117: 301-306.

36 Frates R C Jr, Kaizu TT, Last JA : M ucus glyroproteins secreted by respiratory epithelial tissue from cystic fibrosis patients. Pediatr Res 1983; 17: 30-34.

37 Scharfman A et al: I nteractions between glycoconjugates from human respiratory airways and Pseudomonas aeruginosa. (R eview). A m J R espir Crit Care M ed 1996; 154 (4 Pt 2): S163-S169.

38 Rose MC: Epithelial mucous glycoproteins and cystic fibrosis. (R eview). Horm M etabol Res 1988; 20: 601-608.

39 Gupta R, Jentoft $N$ : The structure of tracheobronchial mucins from cystic fibrosis and control patients. J Biol Chem 1992; 267: 3160-3167.

40 Bear $C$ et al: Purification and functional reconstitution of the cystic fibrosis transmembrane conductance regulator (CFTR). Cell 1992; 68: 809-818.

41 A nderson MP et al: Demonstration that CFTR is a chloride channel by alteration of its anion selectivity. Science 1991; 253 202-205.

42 Collins FS: Cystic fibrosis: molecular biology and therapeutic implications. Science 1992; 256: 774-779.

43 D rumm ML et al: Chloride conductance expressed by delta F 508 and other mutant CFTR s in X enopus oocytes. Science 1991; 254:1797-1799.

44 Boucher $\mathrm{RC}$ et al: $\mathrm{Na}^{+}$transport in cystic fibrosis respiratory epithelia: abnormal basal rate and response to adenylate cyclase activation. J Clin Inv 1986; 78: $1245-1252$

45 A nderson MP, Welsh M J: Calcium and CA M P activate different chloride channels in the apical membrane of normal and cystic fibrosis epithelia. PNAS 1991; 88: 6003-6007.

46 Knowles MR, Clarke LL, Boucher RC. A ctivation by extracellular nucleotides of chloride secretion in the airway epithelia of patients with cystic fibrosis. N E ng J M ed 1991; 325: 533-538.

47 Grubb BR, Vick R N, B oucher R C: Hyperabsorption of $\mathrm{NA}^{+}$and raised $\mathrm{Ca}\left(2^{+}\right)$-mediated $\mathrm{Cl}$-secretion in nasal epithelia of CF mice. Am J Phys 1994; 266((5 Pt 1): C 1478-1483.

48 Stutts MJ et al: CFTR as a CA M P-dependent regulator of sodium channels. Science 1995; 269: 847-850.

49 M all M, H ipper A, Greger R, K unzelmann K : Wild type but not deltaF 508 CFTR inhibits $\mathrm{Na}^{+}$conductance when coexpressed in Xenopus oocytes: FEBS L etters 1996; 381(1-2): 47-52.

50 Ismailov II et al: Regulation of epithelial sodium channels by the cystic fibrosis transmembrane conductance regulator. J Biol Chem 1996; 271(9): 4725-4732.

51 Z hang Y, Y ankaskas J, Wilson J M, E ngelhardt J F : In vivo analysis of fluid transport in cystic fibrosis airway epithelia of bronchial xenografts. Am J Physio Cell Physio 1996; 270: C 1326-C 1335.

$52 \mathrm{E}$ gan $\mathrm{M}$ et al: $\mathrm{D}$ efective regulation of outwardly rectifying $\mathrm{Cl}^{-}$channels by protein $\mathrm{K}$ inase $A$ corrected by insertion to CFTR. N ature 1992; 358: 581-584.
53 Schwiebert E M et al: CFTR regulates outwardly rectifying chloride channels through an autocrine mechanism involving A TP. Cell 1995; 81: 1063-1073.

54 R eddy $M$ M et al: Failure of the cystic fibrosis transmembrane conductance regulator to conduct ATP. Science 1996; 271: 1876-1879.

55 Prat AG, R eisin IL, A usiello DA, Cantiello HF: Cellular A TP release by the cystic fibrosis transmembrane conductance regulator. A m J Physio 1996; 270: C538-C545.

56 Reisin IL et al: The cystic fibrosis transmembrane conductance regulator is a dual ATP and chloride channel. J Biol Chem 1994; 269(32): 20584-20591.

57 Pasyk EA, Foskett JK: Cystic fibrosis transmembrane conductance regulator-associated ATP and adenosine 3'-phosphate 5'-phosphosulfate channels in endoplasmic reticulum and plasma membranes. J Biol Chem 1995; 272: 7746-7751.

58 A I-A wqati Q, B arasch J, Landry D: Chloride channels of intracellular organelles and their potential role in cystic fibrosis. J Exp Biol 1992; 172: 245-266.

59 Lukacs GL et al: The cystic fibrosis transmembrane regulator is present and functional in endosomes: role as a determinant of endosomal pH . J Biol Chem 1992; 267: 14568-14572.

$60 \mathrm{~B}$ arasch J et al: Defective acidification of intracellular organelles in cystic fibrosis. Nature 1991; 352: 70-73.

61 Prince $A$ : A dhesions and receptors of Pseudomonas aeruginosa associated with infection of the respiratory tract. M icrobiol Pathogenesis 1992; 13: 251-260.

62 Sajjan $U$ et al: Binding of nonmucoid Pseudomonas aeruginosa to normal human intestinal mucin and respiratory mucin from patients with cystic fibrosis. J Clin Inv 1992; 89: 657-665.

63 Bradbury NA et al: Regulation of plasma membrane recycling by CFTR. Science 1992; 256: 530-532.

64 B radbury NA, Jilling T, K irk KL, B ridges RJ : R egulated endocytosis in a chloride secretory epithelial cell line. A m J Physio: Cell Physio 1992; 262:C 752-C 759.

65 Bradbury NA, B ridges R J : R ole of membrane trafficking in plasma membrane solute transport. (R eview). A m J Phys 1994; 267(1 Pt 1): C 1-24.

66 Pier G B et al: R ole of mutant CFTR in hypersusceptibility of cystic fibrosis patients to lung infections. Science 1996 271: 64-67.

67 Pier G B, G rout M, Zaidi TS, G oldberg J B: How mutant CFTR may contribute to Pseudomonas aeruginosa infection in cystic fibrosis. A m J Respir Crit Care Med 1996; 154: S175-S182.

68 Pier GB, Grout M: CFTR is a cellular receptor for internalization of $P$ seudomonas aeruginosa. A bstracts of the 96th A nnual M eeting of the A merican Society for Microbiology. 1996 A bstract D -103; p260.

$69 \mathrm{Mcl}$ tosh I, Cutting GR: Cystic fibrosis in transmembrane conductance regulator and the etiology and pathogenesis of cystic fibrosis. (R eview). FA SE B J ournal 1992; 6(10): 2775-2782.

70 Widdicombe J H, Widdicombe J G : R egulation of human airway surface liquid. (R eview). Respiration Physiology 1995; 99(1): 3-12.

71 Welsh MJ, Smith A E: Molecular mechanisms of CFTR chloride channel dysfunction in cystic fibrosis. (R eview). Cell 1993 73(7): 1251-1254. 
72 Jiang $C$ et al: A ltered fluid transport across airway epithelium in cystic fibrosis. Science 1993; 262: 424-427.

73 Smith JJ, Welsh M J: Fluid and electrolyte transport by cultured human airway epithelia. J Clin Inv 1993; 91: 1590-1597.

74 Smith JJ, Karp PH, Welsh M : D efective fluid transport by cystic fibrosis airway epithelia. J Clin Inv 1994; 93(3): 1307-1311.

75 Smith JJ, Travis SM, Greenberg EP, Welsh MJ: Cystic fibrosis airway epithelia fail to kill bacteria because of abnormal airway surface fluid. Cell 1996; 85(2): 229-236.

76 Goldman $M N$ et al: Human $\beta$-defensin- 1 is a saltsensitive antibiotic in lung that is inactivated in cystic fibrosis. Cell 1997; 88(4): 553-560.

77 McCray PB Jr, Bentley L: Human airway epithelia express a beta-defensin. Am J Resp Cell \& Molec Biol 1997; 16: 343-349.

78 Imundo L, Barasch J, Prince A, A I-A wqati Q: Cystic fibrosis epithelial cells have a receptor for pathogenic bacteria on their apical surface. Proc N atl A cad Sci U SA 1995; 92: 3019-3023.

79 Roussel P: Interactions between glyconjugates from human respiratory airways and Pseudomonas aeruginosa. (R eview). A m J Resp Critical Care Medicine 1996; 154: S163-S169.

80 Sajjan SU, Forstner JF: Identification of the mucinbinding adhesion of P seudomonas cepacia isolated from patients with cystic fibrosis. Infection \& Immunity 1992; 60: 1434-1440.

81 Saiman L, Cacalano G, G ruenert D, Prince A : Comparison of adherence of $P$ seudomonas aeruginaosa to respiratory epithelial cells from cystic fibrosis patients and healthy subjects. Infection \& Immunity 1992; 60: 2808-2814.

82 Zar H, Saiman L, Q uittell L, Prince A: Binding of Pseudomonas aeruginosa to respiratory epithelial cells from patients with various mutations in the cystic fibrosis transmembrane regulator. J Pediatr 1995; 126: 230-233.

83 Saiman L, Prince A : P seudomonas aeruginosa pili bind to asialoG M 1 which is increased on the surface of cystic fibrosis epithelial cells. J Clin Inv 1993; 92: 1875-1880.

84 DiMango $E$, Zar $H J$, Bryan R, Prince A: Diverse Pseudomonas aeruginosa gene products stimulate respiratory epithelial cells to produce interleukin-8. J Clin Inv 1995; 96: 2204-2210.

85 A ccurso FJ, Sokol RJ, H ammond KB, A bman SH: Early respiratory course in infants with cystic fibrosis: relevance to newborn screening. (R eview). Pediatr Pulmonol Suppl 1991; 7: 42-45.

86 Bonfield $T L$ et al: Inflammatory cytokines in cystic fibrosis lungs. A m J Respir Crit Care M ed 1995; 152: 2111-2118.

87 Balough $\mathrm{K}$ et al: The relationship between infection and inflammation in the early stages of lung disease from cystic fibrosis. Pediatr Pulmonol 1995; 20: 63-70.

88 A rmstrong D S et al: B ronchoalveolar lavage or oropharyngeal cultures to identify lower respiratory pathogens in infants with cystic fibrosis. Pediatr Pulmonol 1996; 21: 267-275.

89 Yamaya M, Finkbeiner WE, Widdicombe J H : I on transport by cultures of human tracheobronchial submucosal glands. A m J Physio 1991; 261: L 485- L 490.
90 Y amaya M, Finkbeiner WE, Widdicombe JH : A Itered ion transport by tracheal glands in cystic fibrosis. Am J Physio 1991; 261: L 491-L 494.

91 Oppenheimer EH, Esterly JR: Pathology of cystic fibrosis review of the literature and comparison with 146 autopsied cases. In: R osenberg HS, B olande R P (eds). Perspectives in Pediatric Pathology, N ew York Y ear B ook M edical, 1975, pp241-278.

92 Reid L: Measurement of the bronchial mucous gland layer: a diagnosis yardstick in chronic bronchitis. Thorax 1960; 15: 132

93 M eyrick $B, R$ eid $L$ : U Itrastructure of cells in the human bronchial submucosal glands. J A nat 1970; 107: 281-299.

94 B asbaum CB, Jany B, Finkbeiner WE : The serous cell. Ann Rev Physio 1990; 52: 97-113.

$95 \mathrm{~L}$ arsen $\mathrm{E} \mathrm{H}$ : Chloride transport by high-resistance heterocellular epithelia. Physiological Reviews 1991; 71: 235-283.

$96 \mathrm{~K}$ atz U, Scheffey C: The voltage-dependent chloride current conductance of toad skin is localized to mitochondria-rich cells. Biochem Biophys Acta 1986; 861: 480-482.

$97 \mathrm{~L}$ angridge-Smith JE : $\mathrm{Na}$ absorption and $\mathrm{Cl}$ secretion in bovine tracheal epithelium may take place in different cells. J Physiol (L ond) 1985; 237: 61P.

98 Langridge-Smith JE: Interaction between sodium and chloride transport in bovine tracheal epithelium. J Physiol (L ond) 1986; 376: 299-319.

99 Sehgal A, Presente A, Engelhardt JF: D evelopmental expression patterns of CFTR in ferret tracheal surface airway and submucosal gland epithelia. A m J Respir Cell M olec Biol 1996; 15: 122-131.

100 Ferkol T et al: Immunologic responses to gene transfer into mice via the polymeric immunoglobulin receptor. G ene Therapy 1996; 3: 669-678.

101 Ferkol T et al: Gene transfer into the airway epithelium of animals by targeting the polymeric immunoglobulin receptor. J Clin Inv 1995; 95: 493-502.

102 Duan D, Sehgal A, Y ao J, Engelhardt JF: The Lef1 transcription factor expression defines submucosal gland progenitor cell phenotypes for gene therapy in the airway. A m J Respir Cell M olec Biol. (In Press).

103 E ngelhardt J F, Schlossberg H, Y ankaskas J R, D udus L: Progenitor cells of the adult human airway involved in submucosal gland development. D evelopment 1995; 121: 2031-2046.

104 Widdicombe JH, Widdicombe J G : R egulation of human airway surface liquid. R espir Physio 1995; 99: 3-12.

105 Welsh MJ: Electrolyte transport by airway epithelia. Physiol Rev 1987; 67: 1143-1184.

106 Burch LH et al: Relative expression of the human epithelial $\mathrm{Na}^{+}$channel subunits in normal and cystic fibrosis airways. A m J Physiol 1995; 269: C 511-C518.

107 M atsushita K, J r et al: L ocalization of epithelial sodium channel subunit mRNAs in adult rat lung by in situ hybridization. A m J Physiol 1996; 271: L 332-L 339.

108 B onvalet JP, Rossier B, Farman N: Distribution of amiloride-sensitive sodium channel in epithelial tissue. Comptes rendus des seances de la société de Biologie et de Ses Filiales 1995; 189: 169-177. 
109 Duc C et al: Cell-specific expression of epithelial sodium channel alpha, beta, and gamma subunits in aldosteroneresponsive epithelia from the rat: localization by in situ hybridization and immunocytochemistry. J Cell Biol 1994; 127: 1907-1921.

110 Johnson LG et al: Efficiency of gene transfer for restoration of normal airway epithelial function in cystic fibrosis. Nat G en 1992; 2: 21-25.

111 Goldman MJ, Yang Y, Wilson J M: Gene therapy in a xenograft model of cystic fibrosis lung corrects chloride transport more effectively than the sodium defect. $\mathrm{N}$ at Gen 1995; 9: 126-131.

112 Johnson L G, B oyles SE, Wilson J, B oucher R C: N ormalization of raised sodium absorption and raised calciummediated chloride secretion by adenovirus-mediated expression of cystic fibrosis transmembrane conductance regulator in primary human cystic fibrosis airway epithelial cells. J Clin Invest 1995; 95: 1377-1382.

113 Wilson J M : G ene therapy for cystic fibrosis: challenges and future directions. (R eview). J Clin Invest 1995; 96: 2547-2554.

114 Wagner JA, Gardner P: Toward cystic fibrosis gene therapy. (R eview). A nn Rev Med 1997; 48: 203-216.

115 Perricaudet $M$, Stratford-Perricaudet LD : L'adénovirus, un vecteur de thérapie génique: application à des affections pulmonaires (A denovirus, a gene therapy vector: application to lung diseases). Bulletin de l'A cadémie $N$ ationale de $M$ édecine 1995; 179: 463-475.

116 A li M, Lemoine NR, Ring C J : The use of DNA viruses as vectors for gene therapy. (R eview). G ene Therapy 1994; 1: 367-384.

117 Korst RJ et al: Gene therapy for the respiratory manifestations of cystic fibrosis. (R eview). A m J Respir Crit Care M ed 1995; 151: S75-S87.

118 Flotte TR, Carter BJ : A deno-associated virus vectors for gene therapy (R eview). G ene Therapy 1995; 2: 357-362.

119 Yang $Y$ et al: Inactivation of $E 2 a$ in recombinant adenoviruses limits cellular immunity and improves the prospect or gene therapy of cystic fibrosis. Nat G en 1994; 7: 362-369.

$120 \mathrm{~K}$ aplan J M et al: Characterization of factors involved in modulating persistence of transgene expression from recombinant adenovirus in the mouse lung. $\mathrm{H}$ uman $\mathrm{G}$ ene Therapy 1997; 8: 45-56.

121 Yang $Y$, G reenough $\mathrm{K}$, Wilson J M : Transient immune blockade prevents formation of neutralizing antibody to recombinant adenovirus and allows repeated gene transfer to mouse liver. G ene Therapy 1996; 3: 412-420.

122 Hyde SC et al: Correction of the ion transport defect in cystic fibrosis transgenic mice by gene therapy. Nature 1993; 362: 250-255.

123 A Iton E W et al: Non-invasive liposome-mediated gene delivery can correct the ion transport defect in cystic fibrosis mutant mice. N ature G enetic 1993; 5: 135-142.

124 R osenfeld MA et al: In vivo transfer of the human cystic fibrosis transmembrane conductance regulator gene to the airway epithelium. Cell 1992; 68: 143-155.

$125 \mathrm{M}$ astrangeli $\mathrm{A}$ et al: Diversity of airway epithelial cell targets for in vivo recombinant adenovirus-mediated gene transfer. J Clin Invest 1993; 91: 225-234.

126 Engelhardt J F, L itsky L, W ilson J M : I ncreased transgene stability with E 2 mutant recombinant adenoviral vectors delivered to cotton rat lung epithelium. Human Gene Therapy 1994; 5: 1217-1229.

127 Zabner J et al: Safety and efficacy of repetitive adenovirus-mediated transfer of CFTR CDNA to airway epithelia of primates and cotton rats. Nat G en 1994; 6: 75-83.

128 Logan JJ et al: Cationic lipids for reporter gene and CFTR transfer to rat pulmonary epithelium. Gene Therapy 1995; 2: 38-49.

129 E ngel hardt J F et al: D irect gene transfer of human CFTR into human bronchial epithelia of xenografts with E 1 deleted adenoviruses. N at G ene 1993; 4: 27-34.

130 Flotte TR et al: Stable in vivo expression of the cystic fibrosis transmembrane conductance regulator with an adeno-associated virus vector. PNAS 1993; 90: 10613-10617.

131 E ngelhardt J $F$ et al: A denovirus-mediated transfer of the CFTR gene to lung of nonhuman primates: Biological E fficacy Study. H uman G ene Therapy 1993; 4: 759-769.

132 B out $A$ et al: Lung gene therapy: in vivo adenovirusmediated gene transfer to rhesus monkey airway epithelium. H um G ene Therapy 1994; 5: 3-10.

133 Simon $\mathrm{RH}$ et al: A denovirus-mediated transfer of the CFTR gene to lung of non-human primates: toxicity study. H uman G ene Therapy 1993; 4: 771-780.

134 B out $A$ et al: Lung gene therapy: in vivo adenovirusmediated gene transfer to rhesus monkey airway epithelium. H uman G ene Therapy 1994; 5: 3-10.

135 A fione SA et al: In vivo model of adeno-associated virus vector persistence and rescue. J Virol 1996; 70: 3235-3241.

136 Engelhardt JF: M ethods of adenoviral-mediated gene transfer to airway epithelium in methods in molecular biology. Gene Therapy Protocols, Humana Press, Inc, 1996, 169-184.

137 G rubb BR et al: Inefficient gene transfer by adenovirus vector to cystic fibrosis airway epithelia of mice and humans. Nature 1994; 371: 802-806.

138 Goldman MJ, Wilson J M : Expression of alpha $v$ beta 5 integrin is necessary for efficient adenovirus-mediated gene transfer in the human airway. J Virol 1995; 69: 5951-5958.

139 Pickles RJ. Barker PM, Ye H, Boucher R C: Efficient adenovirus-mediated gene transfer to basal but not columnar cells of cartilaginous airway epithelia. $\mathrm{H}$ uman G ene Therapy 1996; 7: 921-931.

140 Pileswki J M, L atoche JL, A rcasoy SM, A lbelda SM: Expression of integrin cell adhesion receptors during human airway epithelial repair in vivo. Am J Physiol (Lung Cell Mol Physol) 1997; 273: L 256-L 263.

141 Yang Y, Su Q, Wilson J M : Role of viral antigens in destructive cellular immune responses to adenovirus vector-transduced cells in mouse lungs. J Virol 1996; 70: 7209-7212.

142 B ergelson J M et al: I solation of a common receptor for Coxsackie $B$ viruses and adenoviruses 2 and 5 . Science 1997; 275: 1320-1323.

143 Flotte TR, A fione SA, Z eitlin PL: A deno-associated virus vector gene expression occurs in nondividing cells in the absence of vector DNA integration. Am J Resp Cell \& M olec Biol 1994; 11: 517-521.

$144 \mathrm{~K}$ earns W G et al: Recombinant adeno-associated virus (A AV-CFTR) vectors do not integrate in a site-specific 
fashion in an immortalized epithelial cell line. Gene Therapy 1996; 3: 748-755.

145 Ponnazhagan $S$ et al: L ack of site-specific integration of the recombinant adeno-associated virus 2 genomes in human cells. H uman G ene Therapy 1997; 8: 275-284.

146 Samulski RJ: A deno-associated virus: integration at a specific chromosomal locus. (R eview) Current O pin in Genet \& Devel 1993; 3: 74-80.

147 Conrad CK et al: Safety of single-dose administration of an adeno-associated virus (A AV)-CFTR vector in the primate lung. Gene Therapy 1996; 3: 658-668.

148 Xiao X, Li J, Samulski RJ: Efficient long-term gene transfer into muscle tissue of immunocompetent mice by adeno-associated virus vector. J Virol 1996; 70: 8098-8108.

149 Fisher KJ et al: Recombinant adeno-associated virus for muscle directed gene therapy. Nature M edicine 1997; 3: 306-312.

150 Ferrari FK, Samulski T, Shenk T, Samulski R J : Secondstrand synthesis is a rate-limiting step for efficient transduction by recombinant adeno-associated virus vectors. J Virol 1996; 70: 3227-3234.
151 Fisher $\mathrm{KJ}$ et al: Transduction with recombinant adenoassociated virus for gene therapy is limited by leadingstrand synthesis. J Virol 1996; 70: 520-532.

152 Wang $G$ et al: Growth factors induced proliferation facilitates retroviral-mediated gene transfer to pulmonary epithelia. A bstract. Ped Pulmonol 1997 S14: 279.

153 Pitt B R et al: R etrovirus-mediated gene transfer in lungs of living fetal sheep. Gene Therapy 1995; 2(5): 344-350.

154 Engelhardt JF, Y ankaskas JR, Wilson JM: In vivo retroviral gene transfer into human bronchial epithelia of xenografts. J Clin Inv 1992; 90: 2598-2607.

$155 \mathrm{M}$ atsui $H$, Johnson $L G, R$ andell $S H$, Boucher R C: Loss of binding and entry of liposome-DNA complexes decreases transfection efficiency in differentiated airway epithelial cells. J Biol Chem 1997; 272 1117-1126.

156 Curiel DT, Pilewski JM, A lbelda SM: Gene therapy approaches for inherited and acquired lung diseases. A m J Respir Cell Molec Biol 1996; 14: 1-18.

157 Ramsey BW, Boat TF: Outcome measures for clinical trials in cystic fibrosis. Summary of a Cystic Fibrosis Foundation consensus conference. J Pediatr 1994; 124: 177-192.

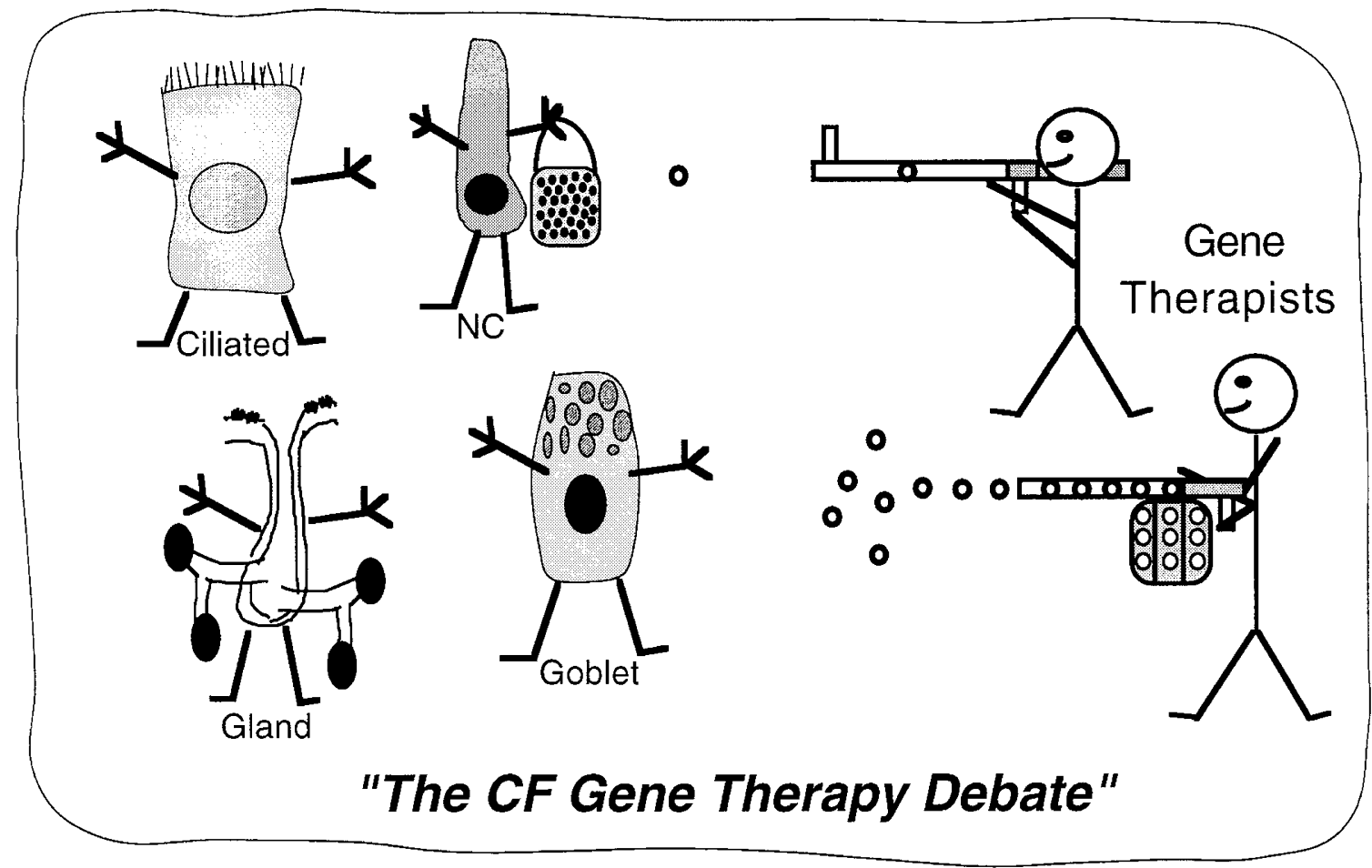

One gene therapist said to the other, "Let me blast them......we'll take them all down!!!"

"No wait, I think I have a clear shot of the one carrying the bacterial baggage!" 